\title{
Forced degradation studies: an essential tool for the formulation development of vaccines
}

\author{
This article was published in the following Dove Press journal: \\ Vaccine: Development and Therapy \\ 12 June 2013 \\ Number of times this article has been viewed
}

\section{Manvi Hasija \\ Lillian Li \\ Nausheen Rahman \\ Salvador F Ausar}

BioProcess Research and Development, Sanofi Pasteur, Toronto, ON, Canada
Correspondence: Salvador F Ausar BioProcess Research and Development, Sanofi Pasteur, 1755 Steeles Ave West, Toronto, ON M3R 3T4, Canada

Email fernando.ausar@sanofipasteur.com
Abstract: Forced degradation studies are typically conducted during the early development phase of vaccine candidates to obtain information on potential degradation pathways, support analytical methods development, and identify potential vaccine stabilizers and optimal conditions for long-term storage. The regulatory guidelines for forced degradation regarding biologics have few to no procedural instructions on how to approach forced degradation studies. In this review, we provide an overview of methods used to study forced degradation in vaccines, mechanisms of degradation, analytical methodology, forced degradation examples conducted for vaccine products, and a summary of stabilizers that are used to influence the results of new vaccine candidates.

Keywords: vaccine, formulation, stability, pathways of degradation, stabilizers

\section{Introduction}

The introduction of mass vaccination programs worldwide is undoubtedly one of the greatest public health achievements of modern times. However, the ability to distribute vaccines to remote areas of the world has been challenged by unavoidable exposure to many stresses such as temperature, light, and agitation that may result in loss of vaccine effectiveness. A major objective of vaccine formulation development is thus to develop a safe and immunogenic composition that can overcome the many challenges and stresses exposed during manufacturing, storage, and distribution.

Forced degradation (FD) studies (or stress studies) are an essential step in vaccine formulation development. Such studies are typically conducted during the early development phase of vaccine products and serve multiple purposes: (1) to obtain information on potential degradation pathways and therefore provide further insight into preformulation and formulation development; (2) to ensure that analytical methods are able to detect degradation products for stability indicating assays and to set up in-process analysis protocols for screening purposes; and (3) to identify potential vaccine stabilizers and optimal conditions for long-term storage. In addition, the design of degradation studies and the resulting stability data are required for regulatory submissions.

The regulatory guidelines for FD are currently very general with few procedural instructions on how to approach FD studies. The International Conference on Harmonization (ICH) provides scientific and regulatory guidance for the pharmaceutical industry of the USA, Europe, and Japan. The ICH provides general guidance about FD studies. They are broad in principal and there are little to no practical 
examples of how to set up adequate stress conditions and appropriate acceptance criteria. ${ }^{1,2}$ Vaccine developers are thus left with numerous gaps for interpretation, including suitability and selection of stress conditions, timing of stress studies, and extent of degradation. A summary of the $\mathrm{ICH}$ guidelines referring to $\mathrm{FD}$ experiments is listed in Table $1 .^{3-11}$

Formulation and FD for protein therapeutics and monoclonal antibodies are extensively covered in the scientific literature, ${ }^{1,12-15}$ however, very few review articles are available specifically on the subject of vaccines. The objective of this review is to provide an overview of the methods used to study FD in vaccines as well as the analytical methodology typically used to assess degradative changes in vaccine components. We also discuss common degradation pathways of vaccine components and the stabilizers used by vaccine developers to prevent or slow down physicochemical degradation reactions.

\section{Mechanisms of vaccine degradation}

A major challenge in vaccine formulation development is identifying the mechanism of degradation responsible for the instability of each component in the formulation. In vaccines and in traditional pharmaceutical products, two basic mechanisms of degradation are largely responsible for product instability: chemical degradation and physical degradation. Chemical degradation involves any kind of process that leads to a break or a formation of new covalent bonds that ultimately generate new chemical species. Alternatively physical degradation involves changes to the physical state of vaccine components such as aggregation, phase transition, or denaturation without altering the chemical composition. Although the two major mechanisms of degradation can be conveniently distinguished, they are often interrelated with well-known connections between chemical degradation reactions and the induction of physical instability in proteins.

\section{Chemical degradation}

In studying chemical degradation in vaccine formulations, it is important to understand that all four large biomolecules produced by living organisms (nucleic acids, lipids, proteins, and polysaccharides) can coexist in a given vaccine formulation. A variety of chemical degradation reactions can take place in such biomolecules. The purpose of this section is to provide readers with a general overview of major chemical degradation pathways of common vaccine components including proteins, nucleic acids, phospholipids (PLs), and polysaccharide-protein conjugates.

Table I Stability and forced degradation requirements in $\mathrm{ICH}$ quality guidelines

ICH guideline title
QIB: Photostability testing of new drug substances and products ${ }^{3}$
Q2(RI): Validation of analytical procedures: text and methodology ${ }^{4}$

Q3A(R2): Impurities in new drug substances ${ }^{5}$

Q3B(R2): Impurities in new drug products ${ }^{6}$

Q5C: Stability testing of biotechnological/biological products ${ }^{7}$

Q5E: Comparability of biotechnological/biological products subject to changes in their manufacturing process ${ }^{8}$

Q6B: Test procedures and acceptance criteria for biotechnological/ biological products ${ }^{9}$

Q8(R2): Pharmaceutical development ${ }^{10}$

QII: Development and manufacture of drug substance"I

Comments

Provides guidance for the generation of photostability studies to support submission in registration applications for new molecular entities.

Forced degradation studies are required for analytical method validation to demonstrate test specificity.

Recommends the use of appropriate stress conditions for validation of analytical procedures applicable to new chemical entities.

Biological/biotechnological products not covered in the guidelines.

Recommends the use of accelerated and stress conditions to support the establishment of expiration date and to support product comparability. Selection of stress conditions to be conducted on a case-by-case basis. The manufacturing process and its changes may potentially produce different degradants and degradation pathways. Recommends forced degradation studies to establish potential product differences in the degradation pathways.

Forced degradation studies can help to understand process related degradants/impurities; justify and rationalize to meet the requirements of setting up the acceptance criteria based on potency and the level of product-related impurities.

Forced degradation studies usually include extended variations (ie, temperature, $\mathrm{pH}$, light, shear), container closure system compatibility, and suitability studies under normal and stressed storage conditions.

Forced degradation studies will provide product knowledge and fulfill quality requirements.

Abbreviation: ICH, International Conference on Harmonization. 


\section{Protein deamidation}

Deamidation is one of the most common chemical degradation pathways in proteins and peptides. In proteins, it occurs when an amide group is removed from asparagine (Asn) and glutamine (Gln) side chains. The effects of deamidation on the biological activity of proteins are unpredictable. In some cases, deamidation can result in a reduction of biological activity, ${ }^{16}$ while in others, biological function is unaltered. ${ }^{17}$ There are reports indicating deamidation as the cause of increased immunogenicity in therapeutic proteins. ${ }^{18,19}$ However, to the best of our knowledge, there are no reports of such changes in the field of vaccines.

Under acidic conditions, deamidation of Asn and Gln will produce aspartate (Asp) and glutamate (Glu), respectively. This is rarely observed in vaccines because it necessitates $\mathrm{pH}$ values lower than 3 , which are seldom seen in vaccine formulations. Under neutral or alkaline conditions (ie, typically a $\mathrm{pH}$ greater than 6), deamidation of Asn residues begins with the generation of a five-membered succinimide ring intermediate. This intermediate is highly unstable and susceptible to subsequent hydrolysis, generating two degradation products - isoaspartate (isoAsp) and Asp. Deamidation of Gln is also possible, but it is not as frequent as Asn deamidation. ${ }^{19}$

Several conditions can facilitate deamidation in proteins. In particular, the $\mathrm{pH}$ dependency on the Asn deamidation reaction has been extensively studied in model peptides. ${ }^{20-22}$ From these studies, it is now clear that the rate of Asn deamidation increases from $\mathrm{pH} 5$ to 8 , due to greater deprotonation of the nitrogen atom in the peptide bond. This, in turn, leads to faster reactivity of the Asn residue. Deamidation is especially important for protein antigens formulated in aluminum hydroxide (AH) adjuvant at neutral $\mathrm{pH} .{ }^{23}$

There is a clear relationship between the local primary sequence of a protein and Asn reactivity. The $\mathrm{N}+1$ amino acid in the primary sequence has been shown to strongly influence the rate of deamidation. ${ }^{24}$ When glycine is the $\mathrm{N}+1$ residue in the primary structure of a protein, it significantly increases the frequency of deamidation. In general, any amino acid with a small side chain as N + 1 (ie, Asn, Ser, or Asp) will lead to faster kinetics of deamidation. Hydrophobic or bulky side chain amino acids after the Asn residue reduce the rate of deamidation, probably by a steric hindrance mechanism that has been proposed to decrease the rate of reactivity. ${ }^{22,24}$ The conformation of the protein can also affect the rate of deamidation. As for other chemical degradation reactions, the rate of deamidation is enhanced by the degree of solvent exposure of the Asn residue.
In general, analysis of chemical modifications in proteins such as deamidation can be accomplished by examining the intact polypeptide or through digestion, using specific enzymes, and subsequently analyzing the resultant peptides by mass spectroscopy (MS). These techniques were successfully used in unadjuvanted Bacillus anthracis protective antigen, ${ }^{25}$ and in multivalent vaccines adsorbed to aluminum salt adjuvants. ${ }^{26}$ From a practical point of view, Asn deamidation can be detected by analytical tools that separate proteins by electrostatic charge. This is due to the fact that a neutral Asn residue is converted to a charged Asp following deamidation. Ionic exchange chromatography and capillary isoelectric focusing are examples of techniques used during preformulation to monitor deamidated isoforms of proteins.

\section{Nonenzymatic cleavage of peptide bonds}

Protein fragmentation, by cleavage of the peptide union, can occur by hydrolysis of peptide bonds at Asp residues under acidic conditions or by $\mathrm{C}$-terminal succinimide formation at Asn residues. Under acidic conditions, the carboxyl group of Asp can act as a proton donor for cleavage of the peptide union through the formation of a cyclic imine intermediate. This reaction classically occurs at the C-terminal side of the residue being more frequent in aspartate-proline (Asp-Pro) bonds. ${ }^{27}$ Sequences containing serine can also form a cyclic imide intermediate that can produce peptide chain cleavage. ${ }^{28}$ This type of cleavage requires low $\mathrm{pH}$ conditions and can be typically seen when conducting FD studies at accelerated temperatures. Asp hydrolysis has been reported for ribonuclease and human epidermal growth factor under accelerated conditions. ${ }^{27}$ Under more physiological $\mathrm{pH}$ conditions, succinimide formation at Asn residues leads to the cleavage of the peptide union. In this case, the side chain amide nitrogen attacks the peptide bond to form a C-terminal succinimide residue and a newly formed amino terminus. ${ }^{27}$

\section{Disulfide exchange}

Disulfide exchange can be observed in proteins at neutral and alkaline $\mathrm{pH}$ conditions and can be accelerated by thiols. This reaction can lead to altered structure, conformational instability and, ultimately, altered antigenicity of protein antigens. Scrambling of disulfides has been reported in numerous proteins and typically results in conformational changes and physical instability of the protein. ${ }^{15,27}$ Incorrect disulfide formation has been reported in lyophilized proteins that can result in conformational changes and aggregation of the protein. ${ }^{29}$ The correct formation of disulfide pairings has been shown to be a key requirement for the correct folding of 
virus-like particles and the development of immunogenicity against hepatitis B major surface antigen. ${ }^{29,30}$

\section{Protein oxidation}

Although oxidation can take place in any protein containing methionine (Met), histidine (His), tryptophan (Trp), tyrosine (Tyr), or cysteine (Cys), it occurs more frequently in sulfurcontaining amino acids. The rate of oxidation can be affected by intrinsic and extrinsic factors. An example of an intrinsic factor is the flexibility of the peptide backbone that can significantly increase the frequency of solvent exposure of sensitive residues. ${ }^{31,32}$ Buffer species, $\mathrm{pH}$, and the presence of divalent metals in the formulation are examples of extrinsic factors that can affect protein flexibility. ${ }^{15}$ Protein oxidation can be site specific (near protein-metal binding sites) or non-site specific, which is typically initiated by light or impurities from buffer or excipients.

Oxidation of Met residues results in conversion to Met sulfoxide, which can be further oxidized to Met sulfone under severe oxidation conditions. The rate of Met oxidation appears to be $\mathrm{pH}$-independent, but is somehow controlled by the degree of solvent accessibility of the Met residue. ${ }^{15} \mathrm{Cys}$ residues in proteins can react with reactive oxygen species (ROS) and oxidize to form intra- or intermolecular disulfide bonds. Other monomolecular byproduct(s), such as sulfenic or cysteic acids, can form as a result of harsher oxidation conditions. ${ }^{27}$ Trp oxidation, although rare, can be observed in pharmaceutical formulations. The main metabolite of Trp oxidation is a kynurenine derivative, which has been identified in monoclonal antibodies by MS. ${ }^{33}$

The detection of protein oxidation is typically conducted by reverse phase high performance liquid chromatography (RP-HPLC), since an increase in protein polarity occurs due to the introduction of carbonyl groups to the oxidized Met residue. Since oxidation of Met residues introduces a net mass change of $16 \mathrm{Da}$, it can be detected by matrix-assisted laser desorption ionization (MALDI)-time of flight MS. Formation of intermolecular disulfide bonds can be easily detected by sodium dodecyl sulfate (SDS) polyacrylamide gel electrophoresis (PAGE; SDS-PAGE) under nonreducing conditions.

Although generally regarded as destructive of protein epitopes, strong oxidants such as $\mathrm{H}_{2} \mathrm{O}_{2}$ have been proposed as physiologically relevant means for producing inactivated viral vaccines. The use of $\mathrm{H}_{2} \mathrm{O}_{2}$ for inactivation of viruses has been recently reported as a new approach for the development of vaccines. ${ }^{34}$

\section{Phospholipid oxidation}

Attenuated enveloped viruses and attenuated bacteria contain lipid bilayers composed primarily of PLs. PLs may also be present in the vaccine as components of liposomes in the formulation of experimental adjuvants. ${ }^{33}$ PLs are sensitive to oxidation, particularly those having unsaturated fatty acyl chains in their molecules. Oxidation in unsaturated fatty acids of PLs is referred to as peroxidation and consists of three major steps: (1) initiation; (2) propagation; and (3) termination. ${ }^{35}$ In the initiation step, ROS induce the formation of PL radical species. These species can then react with molecular oxygen to form highly reactive peroxyl radicals. In the propagation step, free radical molecules generate damage to multiple lipid molecules with the formation of further radical species that are responsible for the perpetuation of the reaction. The final step of termination is achieved when the reaction of two radical species results in the formation of a nonradical PL product or by interaction with an antioxidant such as vitamin E. ${ }^{35} \mathrm{PL}$ oxidation has been reported to increase membrane permeability and induce the formation of transient transmembrane water pores that may elicit damage to the attenuated microorganism used in vaccines. ${ }^{36} \mathrm{PL}$ oxidation can be monitored by a variety of techniques. The simplest technique is ultraviolet (UV) spectroscopy by which the formation of conjugated dienes resulting from oxidation of polyunsaturated fatty acids is detected at $233 \mathrm{~nm}^{37}$

In addition, PL oxidation can be monitored by RP-HPLC with chemiluminescence detection and liquid chromatography-MS that facilitate a complete mapping of oxidized PL species in biological and pharmaceutical samples. ${ }^{38}$

\section{Nucleic acid oxidation}

Nucleic acids can be found as active ingredients in the vaccine formulation, such as plasmid deoxyribonucleic acid (DNA), immunostimulatory molecules (such as cytosinephosphate-guanine oligodeoxynucleotide molecules) or as part of the genome of an attenuated virus or bacterium. Nucleic acids can be susceptible to oxidation particularly in the presence of divalent metals such as $\mathrm{Fe}^{2+}$ and $\mathrm{Cu}^{2+}$. In vitro and in the presence of dissolved oxygen, divalent metals can generate hydroxyl radicals through the Fenton reaction and react with DNA bases and deoxyribose to cause the formation of multiple oxidation products and strand breakage. ${ }^{39}$ There are more than 20 nucleotide base oxidation products identified as a result of oxidation of DNA through hydroxyl radicals. ${ }^{39}$ Moreover, the formation of hydroxyl radicals in vitro has been associated with the presence of phosphate ions in solution containing dissolved oxygen and ferrous iron. ${ }^{40}$ Oxidation of genomic DNA can be a potential cause of inactivation and loss of potency in live attenuated vaccines. ${ }^{41}$ 


\section{Chemical degradation in conjugated vaccines}

Conjugated vaccines are produced by the covalent attachment of a bacteria-derived polysaccharide to a carrier protein with the goal of converting a normally T-cell independent immunogen into a T-cell dependent immunogen. The degradation upon storage typically involves deconjugation by a hydrolytic mechanism resulting in an increase of unbound (free) saccharide content. ${ }^{42}$ For most conjugates, the amount of free saccharide will increase over time and is often the critical factor used to establish the expiry date for the product. In some cases, depolymerization of polysaccharides and liberation of oligomers from the conjugate can be catalyzed by aluminum salts. This was observed for haemophilus influenzae type B conjugated vaccine in the presence of $\mathrm{AH}^{43}$

Peptide conjugated to carrier proteins has been described as experimental vaccine candidates for some infectious diseases such as measles. ${ }^{44}$ Due to the early stage development of these types of vaccines, little information is available in the scientific literature with respect to FD. The mechanism of degradation and methods of detections may be similar to those applicable to protein antigens.

\section{Physical mechanisms of degradation Aggregation}

Aggregation in biological products poses many threats to the biotechnology industry. Moreover, its effects can be detrimental during any stage of the product lifetime, including protein refolding, product purification, sterilization, shipping, and storage. ${ }^{14}$ Although aggregation is typically associated with physical instability of proteins, it can also be observed in other components of the vaccine formulation, such as inorganic adjuvant salts, adjuvant emulsions, lipid-based immunostimulators, or whole attenuated microorganisms. There are many mechanisms by which protein-based antigens can aggregate in vitro. In general, these mechanisms are not mutually exclusive and more than one pathway can occur at the same time..$^{45} \mathrm{~A}$ typical mechanism of protein aggregation includes nucleation, surface induced aggregation, aggregation of conformationally altered monomers, aggregation of chemically modified monomers, and association of native monomers. ${ }^{45}$

Protein molecules have the ability to adsorb onto interfaces, such as those found in vials, syringes, tubing, and other similar containers. ${ }^{46}$ Protein adsorption is typically due to hydrophobic interaction as is the case between nonpolar regions of a protein and air bubbles. During freezing and thawing, proteins and microorganisms may also denature at the ice-liquid interface. ${ }^{46}$

Nucleation is another common mechanism by which protein aggregation may occur. In general, the native monomer of a protein has a low tendency to form small-or moderate-sized oligomers since the process is not thermodynamically favored. However, in the presence of an aggregate of sufficient size, the growth of the "critical nucleus" through the addition of more monomers is favored. ${ }^{45}$ The nucleation mechanism can be divided into homogeneous and heterogeneous nucleation. In homogenous nucleation, the critical nucleus is a product aggregate. If the critical nucleus is an impurity or contaminant, then the process is called heterogeneous nucleation. Such impurities may include, for example, silica particles shed by glass vials and steel particles shed by piston filling pumps. ${ }^{45}$ Antimicrobial preservatives commonly used in multidose vaccines can also have an impact on aggregation. Hutchings et $\mathrm{al}^{47}$ have recently examined the mechanism by which antimicrobial preservatives induce protein aggregation. Interestingly, they have found that these small molecules enhanced partial protein unfolding in local regions that were predicted to be the aggregation "hot-spot." Leachables, such as silicon oil from prefilled syringes, have come under scrutiny from the regulatory agencies due to the formation of visible and subvisible proteinaceous aggregates, which could potentially exhibit unpredictable immune responses. ${ }^{48}$ Although this is a well-recognized issue for protein pharmaceuticals, the link between aggregates and vaccine potency is not completely understood. ${ }^{48,49}$

Solution $\mathrm{pH}$ plays an important role in protein aggregation. The type of charge that a protein has is dictated by the $\mathrm{pH}$ of the solution. Proteins are often stable against aggregation over a specific $\mathrm{pH}$ range and may aggregate rapidly outside this range. Electrostatic interactions on the protein can give rise to unstable protein conformations, thus leading to aggregation. ${ }^{14}$ In addition, conformational stability can also be altered by the formation of salt bridges and other specific charge interactions. ${ }^{14}$ Charges on protein molecules can lead to electrostatic interactions between protein molecules. When proteins are highly charged, assembly of proteins into aggregates is not thermodynamically favored. However, when the protein is at its isoelectric point (pI), the protein possesses both positive and negative charges on its surface, making protein-protein interactions, such as aggregation, highly probable.

Aggregation can also occur in aluminum salt adjuvanted vaccines ${ }^{50}$ conjugated vaccines, and live attenuated vaccines. ${ }^{51}$ The inherent mechanism of aggregation in these types of vaccines is less well characterized due to the complexity of the formulations. Aggregation upon reconstitution was observed in the Bacille Calmette-Guérin vaccine, and was reduced by the elimination of the air-water interface, highlighting the contribution of a surface induced 
aggregation mechanism. ${ }^{52}$ For the case of aluminum salt adjuvants, exposure of the vaccine to subzero temperatures is a well-known factor that induces a significant increase in the particle size and sedimentation rate. ${ }^{53}$ The extent of aluminum salt flocculation appears to depend on a number of factors, including charge on the particles at the formulation $\mathrm{pH}$, excipients, ionic strength of formulation, and concentration of aluminum adjuvant. ${ }^{54}$

\section{Denaturation}

For protein components of vaccines, alteration of secondary, tertiary, or quaternary structure can alter key epitopes or expose nonpolar regions and result in aggregation or precipitation. ${ }^{55}$ Denaturation can also increase solvent accessibility and therefore increase the rate of chemical degradation reactions in labile regions of the protein. ${ }^{15,27,55}$ It can be induced by multiple factors such as exposure to high or low temperatures, chemicals, and high pressure. Temperature-induced denaturation is typically irreversible due to aggregation and has been reported during FD studies in many vaccine candidates including recombinant protein antigens, ${ }^{56,57}$ virus-like particles, ${ }^{58,59}$ and live attenuated microorganisms. ${ }^{60,61}$

In the case of attenuated microorganisms, ${ }^{60,61}$ it is important that all components maintain native conformation. For instance, disruption of the lipid bilayer or denaturation of a key protein needed for viral assembly or for interaction with viral receptors in cells can result in a decrease of vaccine stability. ${ }^{60-64}$ In this context, stabilization of the envelope membrane in measles virus has been recently shown to be important for overall stability as measured by the infectivity assay. ${ }^{61}$ In DNA vaccines, tertiary structure of plasmid DNA is extremely important for efficient delivery to target cells. The supercoiled DNA isoform is generally considered to be the most desired conformation for plasmid DNA in pharmaceuticals. ${ }^{40,65}$ However, its conformational integrity is usually damaged by hydrolytic and oxidative reactions that lead to the formation of different degradation products, including open circular and linear forms of the plasmid. ${ }^{40}$

\section{Adsorption to surfaces}

During bioprocessing vaccines are in contact with multiple surfaces. It is not uncommon to observe adsorption of vaccine components to surfaces, such as glass, plastic, and stainless steel containers, rubber stoppers, and prefilled syringes. Shedding material from prefilled syringes has been reported to cause adsorption and physical instability of monoclonal antibodies and vaccines antigens. ${ }^{48}$ There are a number of factors that influence adsorption of biological products to surfaces, including temperature, $\mathrm{pH}$, ionic strength, surface tension, and the nature of the surface. The main consequence of adsorption is the structural perturbation of the protein adsorbed to the surface and induction of aggregation by a nucleation-based mechanism. ${ }^{45}$ The process is believed to begin with the adsorption of native or partially unfolded proteins to the interface. This is followed by a surface tension-driven alteration of the protein's structural integrity and the subsequent growth of aggregates at the interface and, eventually, in the bulk solution. ${ }^{15}$ Surface adsorption of proteins, lipids, and attenuated microorganisms has been reported to cause membrane filtration fouling. ${ }^{66-68}$

\section{Analytical tools for forced degradation analysis}

In vivo testing is widely used in the development and assessment of potency and safety for new vaccines. Based on the principle of the $3 \mathrm{R}$ concept by Russell and Burch, ${ }^{69}$ replacement, reduction, and refinement of animal tests can be achieved by improved characterization methods applied to well-developed vaccine production procedures. In this section, in vivo and in vitro vaccine characterization methods that support FD studies are discussed.

\section{Potency testing}

Potency testing is the specific ability of a product to affect a given result, either by a controlled laboratory test or by controlled clinical data. In order to measure product stability, a quantitative test for potency is required for biologically active components of the vaccine..$^{70}$ Regulatory agencies require that vaccines intended for the market be tested for their potential to induce protective immunity after immunization. Potency tests for live attenuated vaccines and inactivated vaccines are designed differently. Generally, in vitro testing as a potency assay is used for live, attenuated vaccines. Alternatively, in vivo potency testing is required for inactivated vaccines, although exceptions do exist. Animal immunogenicity testing commonly includes immunization challenge tests under an experimental model. Depending on the vaccine, different endpoints can be used such as a death/survival ratio, clinical signs, and colonization. When challenge models are not available, serology following immunization is measured. In addition, neutralization of the pathogen by the functional antibody can also be measured.

Variability in results between replicates and/or laboratories is common when conducting animal testing; this 
could be due to genetic differences of the animals used. Therefore, reproducibility is fairly poor with respect to potency testing of vaccines. ${ }^{71}$ Furthermore, animal testing has been a challenge with animal rights groups lobbying for discontinuation. In the field of vaccines, biological assays are often used and FD studies are critical for establishing robustness and suitability of biological methods. Thanks to advances in analytical methodologies, there is a greater interest in the application of in vitro techniques for product characterization. However, changes observed by physiochemical methods may not always show an alteration in potency or efficacy testing. We have recently observed this phenomenon when studying the impact of degradation on the immunogenicity of a trivalent recombinant protein vaccine..$^{72}$ In this study, we observed that a decrease in physicochemical stability of the antigen PhtD did not correlate with immunogenicity in mice. Although it was not clear why a correlation was not observed, it was hypothesized that immunodominant regions of the protein were not significantly affected by the pH-catalyzed chemical degradation. ${ }^{72}$

\section{Physicochemical testing}

It is very difficult to develop a successful in vitro test that correlates with potency. In general, the potency of a vaccine is determined by antigen structure and composition. There are many techniques used today to obtain information about vaccine antigen(s) structure and composition (Table 2). The use of several analytical techniques is required to characterize a vaccine antigen. A fingerprint approach may be used in which several nonrelated analytical techniques are applied to compare different batches and monitor the stability of the vaccine component over time. This fingerprint approach is quite valuable in the bioprocessing stages of new vaccines, since any changes in the manufacturing process requires comparability demonstrating the degree of similarity between the "old" and the "new" lots. Structural information of protein antigens can be obtained from three categories of techniques: analytical, spectroscopy, and immunochemistry.

\section{Differential scanning calorimetry (DSC)}

Differential scanning is based on the difference in heat applied to a compartment containing a sample with respect to a compartment containing the buffer. This results in a heat flow that can either be positive, in the case of samples having endothermic transition or negative, for exothermic events. The thermal stability of various vaccine components such as proteins, nucleic acids, and viral particles can be assessed by thermally induced transitions detected by differential scanning calorimetry (DSC). In this context, DSC was successfully used to characterize the $\mathrm{pH}$ sensitivity of Norwalk virus-like particles vaccine, ${ }^{58}$ polio and influenza viruses, ${ }^{73}$ and model antigens adsorbed to aluminum salt adjuvants. ${ }^{74}$ DSC is available in high throughput mode and has been also shown to be useful when conducting preformulation, excipient screening, and stability assessments. ${ }^{75}$

\section{Mass spectrometry (MS)}

MS is a technique in which the molecular weight of biological compounds can be measured to a high degree of accuracy and sensitivity. Epitope identity, antigen structure, and antigen processing can all be detected by using this technology. MS is based on three steps: ionization, separation of the formed ions into different mass/charge ratios, and detection of the separated ions. This tool is used increasingly for identifying low level biological impurities in drug substance and drug product. Fragments of digested proteins can be analyzed with or without a preceding chromatographic separation, which results in sequence determination. ${ }^{76}$ There are several types of MS ionization techniques that can be used for antigen determination and they include MALDI, electrospray ionization, and tandem mass spectrometry (MS/MS). MALDI and electrospray ionization MS techniques are considered "soft" ionization techniques as they do not induce fragmentation, whereas MS/MS acquires structural information of peptide sequences and induces high fragmentation. Furthermore, MS can be used as a tool to advance the design of new human leukocyte antigenassociated specific peptides that are pathogenic-derived and may potentially lead to prophylactic vaccine candidates. ${ }^{77}$ The utility of MS for assessing chemical degradation of vaccines has been recently described by Estey et al. ${ }^{26}$ It was demonstrated that adsorption to aluminum salts can impact the chemical degradation pathway of protein antigens during long-term storage. ${ }^{26}$ Furthermore, liquid chromatography/ MS can be used to detect nonenzymatic cleavage and identify the cleave sites in the specific antigen.

\section{Circular dichroism (CD)}

Circular dichroism (CD) is used to detect conformational changes in nucleic acid, as well as in protein secondary (far-UV CD) and tertiary (near-UV CD) structure. It uses circularly polarized light to detect asymmetry in a compound. Different absorption of the left-handed and right-handed polarized light by molecules provides a characteristic spectrum that allows for conformational change detection. The detection of asymmetry in peptides results in differences in 


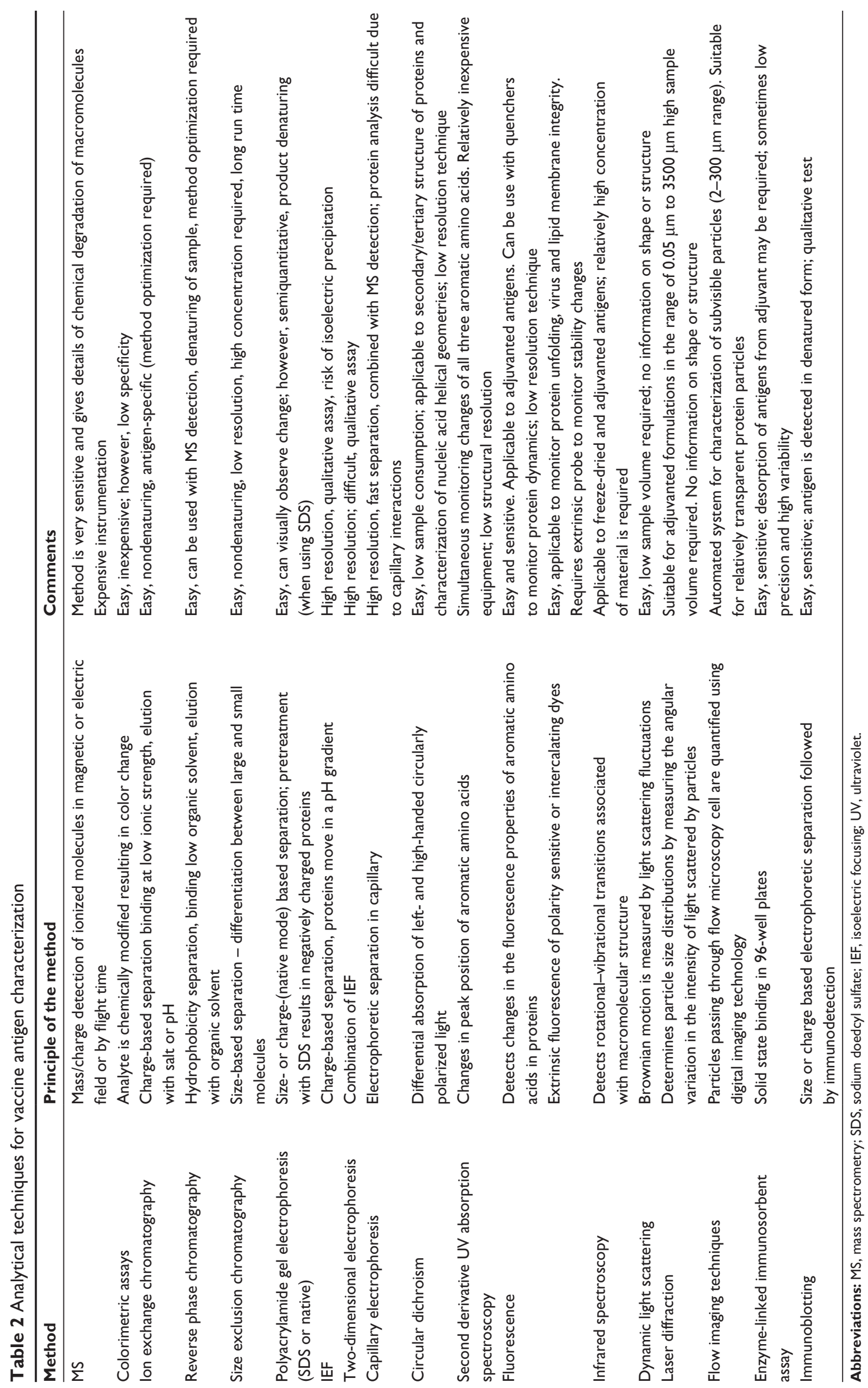


absorption in the far-UV region, identifying the percentage of $\alpha$-helix, $\beta$-sheet, $\beta$-turn, and random coil structure. ${ }^{76}$ Alternatively, absorbance differences in the near-UV region relates to the orientation of key absorbing amino acid residues such as Trp, Tyr, phenylalanine, and cystine, which in turn provide information on the tertiary conformation of the protein molecule. $\mathrm{CD}$ is used to detect changes in the peptide structure when selecting for formulation excipients under stress conditions. CD has shown to be a useful technique when assessing the effects of formaldehyde concentrations on conformational stability of diphtheria toxin and toxoids. ${ }^{78}$ A change in the near-UV CD spectra by CD analysis indicates that formaldehyde induces perturbations of the tertiary structure for the diphtheria toxin. ${ }^{78}$ Furthermore, CD is used to characterize different batches that are monitored within stability programs for vaccine antigens.

\section{Fluorescence spectroscopy (FS)}

Fluorescence spectroscopy (FS) is a technique commonly used to detect the conformational stability of protein molecules. This technique is dependent on fluorescent amino acids, such as Trp, Tyr, and phenylalanine. Trp is excited at $295 \mathrm{~nm}$. For instance, upon protein denaturation Trp residues are exposed to a more polar environment resulting in a red shift in the wavelength of maximum fluorescence emission. The difference between the maximum native protein and the denatured protein can be measured to determine the stability of the antigen and formulated antigen. In addition to unfolded proteins detectable by this technique, covalent changes in fluorescent amino acids can also be demonstrated. This was assessed using tetanus toxoid when stored at low $\mathrm{pH}$ conditions in the form of polymeric microspheres. ${ }^{79}$

We have recently developed a method that uses extrinsic fluorescence of dyes to monitor the physical stability of antigens in the presence of aluminum salt adjuvants. ${ }^{80} \mathrm{By}$ this method, FD of antigens at low concentrations can be accomplished in a few hours using low volumes of material. Figure 1 shows the effect of $\mathrm{pH}$ on the thermal stability of a pneumococcal vaccine candidate adsorbed to aluminum salts. A distinct $\mathrm{pH}$ behavior was observed when the protein was adsorbed to AH possibly due to the presence of phosphate buffer at neutral $\mathrm{pH}$, which decreased the microenvironment $\mathrm{pH}$ and the strength of adsorption. ${ }^{80}$

\section{Fourier transform infrared spectroscopy (FTIR)}

Fourier transform infrared spectroscopy (FTIR) is a method used to detect the secondary structure of proteins and nucleic

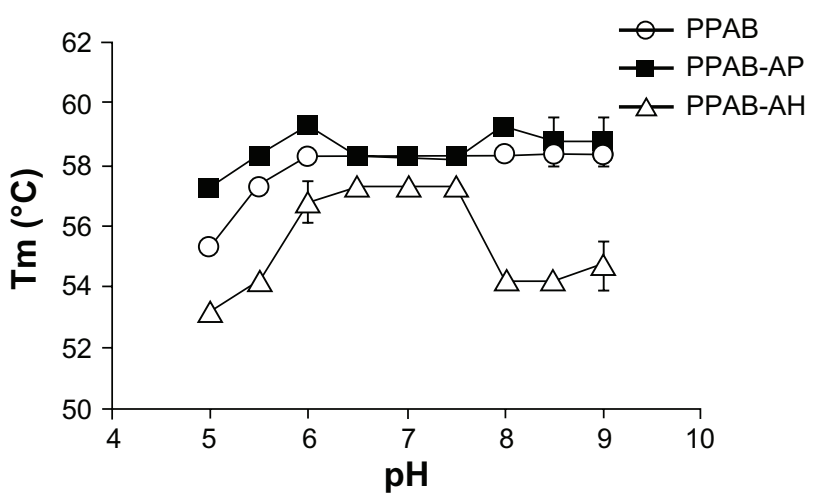

Figure I Evaluation of PPAB physical stability adsorbed to Al adjuvants by extrinsic fluorescence of SYPRO $(\mathrm{R})$ orange. ${ }^{80}$

Notes: PPAB was adjuvanted with $\mathrm{AH}$ or $\mathrm{AP}$ at different $\mathrm{pH}$ values, and the $\mathrm{Tm}$ values were obtained by derivative analysis of the fluorescence traces. Distinct effect of $\mathrm{pH}$ is observed for the protein adsorbed to $\mathrm{AH}$. Copyright 20II, reproduction with permission of Wiley-Liss, Inc. Ausar SF, Chan J, Hoque W, James O, Jayasundara K, Harper K. Application of extrinsic fluorescence spectroscopy for the high throughput formulation screening of aluminum-adjuvanted vaccines. J Pharm Sci. 201।;100(2):431-440.80

Abbreviations: PPAB, pneumoccoccal protein antigen B; Tm, melting temperature; $\mathrm{AP}$, aluminum phosphate; $\mathrm{AH}$, aluminum hydroxide.

acids and complexes such as viruses. This technique uses radiation in the infrared region ranging from $2500-5000 \mathrm{~nm}$ in order to excite molecules. For proteins, amide regions 1, 2, and 3 signals are monitored for secondary structure. For DNA-based vaccines, vibrational bands in which the position of peaks are determined from nucleic acid bases and phosphate groups are used to estimate the secondary structure. Furthermore, FTIR can resolve and identify the molecular profile of conjugate vaccines in which lipid or carbohydrates are present. Unfortunately, relatively high protein concentration is required for this technique, which may be difficult to attain when conducting FD studies in the liquid state. Nevertheless, FTIR is highly recommended for lyophilized formulations since light scattering does not interfere with the dried material. ${ }^{76}$ For example, this technology was used to assess the secondary structure of lyophilized tetanus toxoid. ${ }^{81}$ FTIR can be used to detect the secondary structure of proteins when adsorbed to aluminum adjuvants since optical turbidity of the adjuvant suspension does not affect the measurements. In a study, it was found that a recombinant ricin A-chain vaccine (RTA 1-33/44-198) adsorbed to aluminum adjuvant exhibited a small change in secondary structure using FTIR technology. ${ }^{82}$

\section{Liquid chromatography}

High performance liquid chromatography (HPLC) is a common tool used to separate analytes based on their size, charge, hydrophobicity or affinity. Size exclusion 
chromatography is a method used regularly to determine aggregation behavior for characterization and stability of protein antigens, conjugated vaccines, as well as viral vaccines. ${ }^{83}$ Other techniques, such as ion exchange, reverse phase and hydrophobic interaction chromatography are all alternative methods that can be used for vaccine candidates. In the case of polysaccharide-conjugated vaccines, quantification and catalytic depolymerization of polysaccharide in the presence of $\mathrm{AH}$ can be monitored by high-performance anion-exchange chromatography with pulsed amperometric detection. ${ }^{43}$ Although HPLC can be used to separate antigens and degradation products in vaccine preparations, it often requires stringent separation methods of antigens from aluminum adjuvant prior to analysis..$^{75,83,72}$

\section{Electrophoretic techniques}

Polyacrylamide gel electrophoresis (PAGE) is widely used for analysis of protein-based vaccine components. The technique is used to reveal protein physical properties, protein-protein interactions, proteolysis, and for detecting changes in charged groups (ie, proteins treated with formaldehyde). Generally, PAGE is run under reducing conditions and in the presence of the anionic detergent sodium dodecyl sulfate (sds). Under these conditions, proteins are fully unfolded and have approximately the same mass-to-charge ratio. The migration distance is proportional to the apparent mass of the protein. Furthermore, SDS-PAGE is run under nonreducing conditions, which leaves disulphide bonds intact, and provides information about tertiary and quaternary structure. Finally, native PAGE can also be performed, which is in the absence of SDS and reducing agents. In this case, the native structure and composition are retained. These techniques can be used as a starting point to study protein fragmentation due to nonenzymatic cleavage, disulphide exchange, and aggregation. Antigens can be identified in gels by blotting and detection with antibodies, a technique referred to as Western blotting. Western blotting is considered to be a qualitative assay in which antigens in a complex mixture can be identified to be present and their molecular weight confirmed. ${ }^{76}$

\section{Immunochemical testing}

In vaccines, antigenicity is defined as the ability of an antigen to bind to a specific antibody. It is often expressed as a measurement of concentration, and is distinct from antigen concentration. The majority of antigenicity measurements are conducted using the enzyme-linked immunosorbent assay (ELISA) technique for vaccine formulations. Apart from ELISA, immunochemical tests such as radioimmunoassay, nonlabeled immunoassays, and biosensor analysis can also be used to determine antigenicity.

ELISA is a method used in industry and academia to determine the antigenicity of a vaccine. The result is an antigen concentration that gives an average epitope concentration and epitope quantity. This concentration is calculated relative to a reference, preferably an international standard used to calibrate the "in house" standard. ELISA antigenicity tests can vary enormously in both reproducibility and repeatability.

\section{Infectious titer assay (plaque assay)}

Plaque assay measures the concentration of viruses in a sample for determining the quantity of infectious virus. It is considered the gold standard in virus detection; however, it should be standardized and evaluated for performance and reproducibility for specific viruses when conducted between laboratories. The principle of the technique is to measure the ability of an infectious virus to form a "plaque" on a confluent monolayer culture of cells. A plaque is formed as a result of infection of one cell by a virus particle followed by the replication of that virus and, eventually, the death of the infected cell. The newly replicated virus particle will then infect and kill surrounding cells. The culture will then be stained with dye that stains only viable cells and not the dead cells. Therefore, the dead cells in the plaque will appear unstained against the colored background. This assay is used to assess viral vaccine stability. However, it possesses high variability and low throughput since it can take between 2 to 14 days to complete a test run. In addition, as a loss of titer is captured, this assay does not indicate the underlying mechanism of degradation.

\section{Particle size analysis}

Various methods are used by vaccine developers to characterize aggregation and quantify particle sizes. Many biopharmaceuticals are challenged by regulatory agencies to control and fully characterize vaccine aggregation during the manufacturing process and/or the storage period. It is well known in the literature that aggregates may potentially cause adverse effects, such as a change in the immune response that may impact drug efficacy. ${ }^{85}$ In order to control and characterize particulates, a range of analytical techniques for characterization must be used. Several methods are required in order to fully analyze a broad range of particle sizes. Unfortunately, there is no single analytical method that covers the entire size range. Different methods are thus used to cover particle size ranges from nanometers to micrometers to large visible particles. Therefore, 
it is recommended that a comparison of analytical results is conducted using various orthogonal methods. ${ }^{86}$

Methods that quantify both soluble and insoluble aggregates as well as estimate size distribution include (but are not limited to): dynamic light scattering, nanoparticle tracking analysis, light obscuration, analytical ultracentrifugation, coulter counter, laser diffraction, FlowCAM ${ }^{\circledR}$ (Fluid Imaging Technologies, Yarmouth, ME, USA) and Micro-Flow Imaging ${ }^{\mathrm{TM}}$ (MFI'T Micro-Flo Imagaing, Ottawa, ON, Canada). Flow imaging and laser diffraction will be briefly discussed, as they are highly used in the vaccine industry to demonstrate identifiable trend changes in particle populations that often go undetected.

Flow imaging is a sensitive technique used to quantify and characterize highly transparent particles. There are basically two instruments available for flow imaging analysis:
FlowCam $^{\circledR}$ and MFI $^{\mathrm{TM}}$. A comparison of the two techniques has been recently reported in the literature. ${ }^{87}$ These technologies use integrated digital microscopy, microfluidics, and image processing into a single instrument for automatic analysis of particles or cells suspended in liquids. MFI'TM has the ability to capture images from the sample as it passes through the flow cell's sensing zone. Visual verification can be completed using this technique wherein the images are displayed on the system monitor in real-time. As shown in Figure 2, an agitation study on a recombinant protein antigen was conducted using the $\mathrm{MFI}^{\mathrm{TM}}$ methodology to analyze formulations based on concentration of particles. Greater particle counts and size were observed for the control (Tris $\mathrm{pH}$ 7.4) and Tris acetate $\mathrm{pH}$ 6.5 formulation compared to the formulation containing $0.1 \%$ Pluoronic $^{\circledR}$ F68 (Life Technologies, Carlsbad, CA, USA).

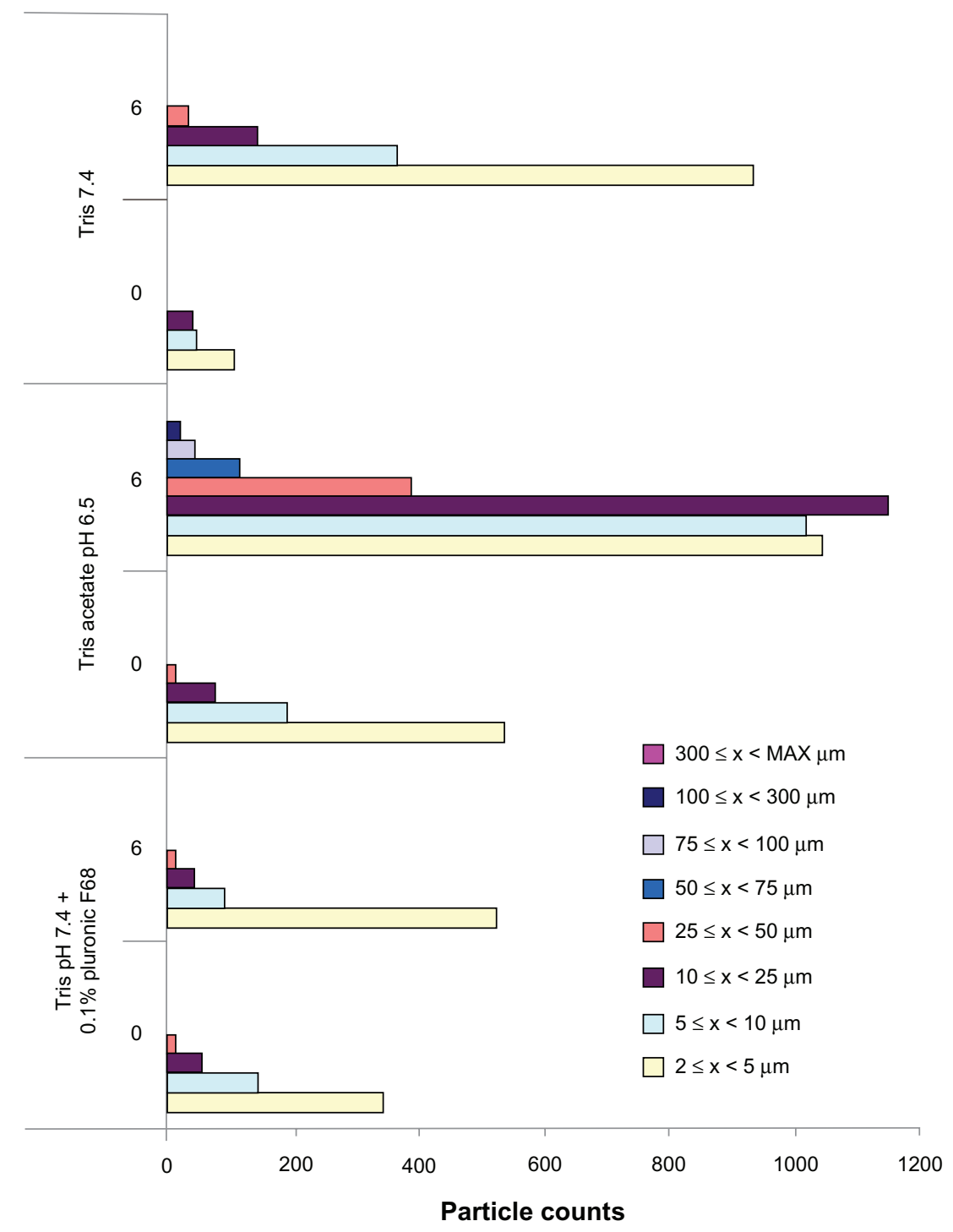

Figure 2 Effects of formulation on agitated recombinant protein using microflow imaging technology for particle counts and characterization. Notes: Recombinant protein antigen was agitated for up to 6 hours, and particle size monitored by microflow imaging in the range of $2 \mu \mathrm{m}$ to $300 \mu \mathrm{m}$. 
Laser diffraction measures particle size distribution by measuring the angular variation in the intensity of light scattered as a laser beam passes through a dispersed particulate sample. Small particles scatter light at large angles, whereas large particles scatter light at small angles. Using the Mie theory of light scattering, the data obtained for the angular scattering intensity is used to calculate the size of the particles responsible for creating the scattering pattern. The particle size is reported as a volume-equivalent sphere diameter. Benefits of using this technology include the fact that a wide dynamic range (from submicron to the millimeter size) can be analyzed including adjuvanted proteins.

\section{Methods of forced degradation}

FD studies involve the exposure of vaccine samples that are considered representative of the manufacturing process for the drug substance or the drug product to various external stress conditions, including heat, humidity, freeze/thaw, acid/base hydrolysis, oxidation, and light. In a highly popular field of vaccines, it is important to obtain significant, measurable progress with FD studies in a timely manner. FD studies are short in duration and are performed under varying stress conditions, which will be described here. Vaccine formulation robustness is extremely important since there are various external stresses applied during production, filling, storage and shipment. The data obtained from FD studies can assist with the development of stability indicating assays, formulation design, selecting normal storage conditions and determining the duration for time out of refrigeration during manufacturing. It is highly encouraged in the industry to initiate FD studies on the drug substance and the drug product prior to Phase I development, despite ICH guidelines not indicating a regulatory requirement for these studies until at least clinical Phase III development. Nonetheless, there is good reasoning to initiate these studies prior to Phase I, most importantly in that they aid in the development of stability indicating methods where potential degradation products can be identified. Consequently, this further expands the understanding of degradation pathways, underlying mechanisms and stabilizer screening. Should a change arise in later development stages, a more comprehensive understanding of the vaccine's degradation will facilitate a smoother transition between development phases where extensive bridging studies would be required. A general guideline for conducting FD studies and stress testing is shown in Table 3.

\section{Thermal stress}

Vaccines are typically stored under refrigerated conditions $\left(2^{\circ} \mathrm{C}\right.$ to $\left.8^{\circ} \mathrm{C}\right)$. Most liquid formulated vaccines have been developed for this type of storage. However, under either elevated or subzero temperatures, stability of the vaccine may be compromised. The most widespread stress condition used in the industry is thermal stress. An increase in temperature is known to cause physical instabilities such as altering tertiary structure and aggregation of proteins, as well as chemical instabilities, such as dissociation of polysaccharides from the protein carrier in polysaccharide conjugated vaccines. A combination of the two may be the cause of reduced infectivity for live-attenuated virus vaccines exposed to high temperatures. All of these changes in the vaccine can be assessed when performing studies under extreme temperatures.

An appropriate temperature for thermal stress testing needs to be selected on a case-by-case approach. As a rough guidance, stress temperatures of at least a few degrees to $10^{\circ}$ below the melting temperature $\left(\mathrm{T}_{\mathrm{m}}\right)$ can be studied. Stability conclusions are often impossible if the temperature conditions are studied at or above the $\mathrm{T}_{\mathrm{m}}$, where severe aggregation and/or protein unfolding may occur. Moreover, degradation products may form that are less relevant to the product degrading in a natural environment. Techniques such as DSC, CD, FTIR, and intrinsic and extrinsic FS, can be used to determine the $\mathrm{T}_{\mathrm{m}}$ of a protein. ${ }^{1}$

In combination with thermal stress, extreme $\mathrm{pH}$ studies can aid in evaluating whether or not the vaccine component has a particular instability as a function of $\mathrm{pH}$. Different buffering agents, hydrochloric acid, and/or sodium hydroxide solutions are generally used for studying the effect of $\mathrm{pH}$ on vaccine degradation. Stress studies designed for extreme acidic or basic $\mathrm{pH}$ are typically initiated at room and at elevated temperatures $\left(50^{\circ} \mathrm{C}-70^{\circ} \mathrm{C}\right)$ for up to 7 days. Alternatively thermal denaturation experiments can be conducted using CD, DSC, and FS to study the effect of $\mathrm{pH}$ on the $\mathrm{T}_{\mathrm{m}}$ of the antigens. For example such studies were conducted in the case of measles, ${ }^{61}$ the Norwalk virus,${ }^{58}$ the respiratory syncytial virus, ${ }^{60}$ and the hookworm vaccine. ${ }^{88}$

As an example of thermal and $\mathrm{pH}$ stresses, Figure 3 shows the thermal stability of an enveloped attenuated virus when monitored by extrinsic fluorescence. The method was implemented in our laboratory and uses intercalating dyes to detect the exposure of viral DNA upon capsid disruption as an indicator of viral thermal stability. Figure 3A shows the thermal profile of an enveloped virus exposed to increasing temperatures. Temperature induced viral disruption was 
Table 3 Overview of forced degradation methods for new vaccine candidates

\begin{tabular}{|c|c|c|c|c|c|}
\hline Stress type & $\begin{array}{l}\text { Drug } \\
\text { substance }\end{array}$ & $\begin{array}{l}\text { Drug } \\
\text { product }\end{array}$ & $\begin{array}{l}\text { Attenuated } \\
\text { microorganisms }\end{array}$ & Recombinant protein & Immunostimulator/adjuvant \\
\hline & & & \multicolumn{3}{|c|}{$\begin{array}{l}\text { Thermal denaturation } \mathrm{pH} \text { range } 3-9 \text { (ie, citric phosphate buffer) } \\
\text { Ramping temperature } 10^{\circ} \mathrm{C}-95^{\circ} \mathrm{C}\end{array}$} \\
\hline $\begin{array}{l}\text { Extreme } \mathrm{pH} \text { (acidic/ } \\
\text { basic conditions) }\end{array}$ & $\sqrt{ }$ & $\sqrt{ }$ & $\begin{array}{l}\text { Isothermal incubation } \\
0.1-\mathrm{I} .0 \mathrm{~N} \mathrm{HCl} / \mathrm{NaOH} \text {, } \\
\mathrm{I}-7 \text { days (up to } 45^{\circ} \mathrm{C} \text { ) }\end{array}$ & $\begin{array}{l}\text { Isothermal incubation } \\
0 . \mathrm{I}-\mathrm{I} .0 \mathrm{~N} \mathrm{HCl} / \mathrm{NaOH}, \\
\mathrm{I}-7 \text { days }\left(25^{\circ} \mathrm{C} \text { to } 60^{\circ} \mathrm{C}\right)\end{array}$ & $\begin{array}{l}\text { Isothermal incubation } 0.1-1.0 \mathrm{NHCl} / \\
\mathrm{NaOH}, \mathrm{I}-7 \text { days }\left(25^{\circ} \mathrm{C} \text { to } 75^{\circ} \mathrm{C}\right)\end{array}$ \\
\hline Oxidation & $\sqrt{ }$ & $\sqrt{ }$ & $\begin{array}{l}0.001 \%-0.01 \% \mathrm{H}_{2} \mathrm{O}_{2} \\
\text { room temperature }\end{array}$ & $\begin{array}{l}0.01 \%-0.1 \% \mathrm{H}_{2} \mathrm{O}_{2} \\
25^{\circ} \mathrm{C}-60^{\circ} \mathrm{C}\end{array}$ & $0.01 \%-0.1 \% \mathrm{H}_{2} \mathrm{O}_{2}, 45^{\circ} \mathrm{C}-60^{\circ} \mathrm{C}$ \\
\hline Photodegradation & & $\sqrt{ }$ & $\begin{array}{l}\text { Stepwise increase to } \\
\text { confirmatory conditions } \\
\text { (ie, } 600 \mathrm{klux} / \text { hour visible } \\
\text { light, } 600 \mathrm{~W} / \mathrm{hour} / \mathrm{m}^{2} \mathrm{UV} \text { ) }\end{array}$ & $\begin{array}{l}>1.2 \text { million lux hours } \\
\text { visible, } 200 \mathrm{wh} / \mathrm{m}^{2} \mathrm{UV}\end{array}$ & $\begin{array}{l}>1.2 \text { million lux hours visible, } 200 \\
\text { wh } / \mathrm{m}^{2} \text { UV }\end{array}$ \\
\hline Thermal & $\sqrt{ }$ & $\sqrt{ }$ & $\begin{array}{l}\text { Up to } 45^{\circ} \mathrm{C} \text {, up to } 4 \text { weeks } \\
\text { (varies depending on } \\
\text { headspace and if oxidation } \\
\text { is expected) }\end{array}$ & $\begin{array}{l}40^{\circ} \mathrm{C}-60^{\circ} \mathrm{C} \text {, up to } \\
12 \text { weeks }\end{array}$ & $40^{\circ} \mathrm{C}-70^{\circ} \mathrm{C}$, up to $12-24$ weeks \\
\hline Thermal/humidity & & $\sqrt{ }$ & $\begin{array}{l}45^{\circ} \mathrm{C}-70^{\circ} \mathrm{C} / 75 \% \text { relative } \\
\text { humidity }\end{array}$ & $\begin{array}{l}45^{\circ} \mathrm{C}-70^{\circ} \mathrm{C} / 75 \% \text { relative } \\
\text { humidity }\end{array}$ & $45^{\circ} \mathrm{C}-70^{\circ} \mathrm{C} / 75 \%$ relative humidity \\
\hline Mechanical stress & & $\sqrt{ }$ & $\begin{array}{l}\text { Stepwise increase up to } \\
350 \mathrm{rpm} \text { for } 3.5 \text { hours }\end{array}$ & $\begin{array}{l}350 \text { rpm for up to } \\
72 \text { hours }\end{array}$ & $350 \mathrm{rpm}$ for up to 72 hours \\
\hline Freeze-thaw stress & $\sqrt{ }$ & $\sqrt{ }$ & $3-5$ cycles of controlled free & ing $\left(-20^{\circ} \mathrm{C}\right.$ or $\left.-70^{\circ} \mathrm{C}\right)$ and $t$ & awing at room temperature \\
\hline
\end{tabular}

Abbreviation: UV, ultraviolet.

detected by an increase in the fluorescence intensity with a transition temperature near $54^{\circ} \mathrm{C}$. This technique can be used to study $\mathrm{pH}$ stress as well; as shown in Figure $3 \mathrm{~B}$, pH has a significant impact on virus thermal stability. A complex thermal stability profile was observed as a function of $\mathrm{pH}$ with optimal stability falling in the $\mathrm{pH}$ range of 6.5 to 6.8 .

Determining the shelf life of a biologic can be slow and time consuming when trending real-time data in the effort to bring a new drug product to the market. In today's industry, there is a desire to predictably determine the shelf life of the drug product under accelerated conditions. However, this may not be possible or accurate, since there may be limited predictability due to the presence of complex and multiple degradation pathways, which may have different degrees of temperature dependence. Nonetheless, focusing on simple degradation pathways, the degradation reactions must follow (pseudo) first-order reactions and undergo simple chemical degradation reactions. The effects of temperature on the thermal degradation of an antigen can be studied using the Arrhenius model.

Using the Arrhenius equation, a plot of the natural logarithm of the rate constants versus the inverse of the absolute temperature will yield a line where the slope of the line equals the activation energy. A typical chemical reaction under first order kinetics shows activation energies ranging from $10-30 \mathrm{kcal} / \mathrm{mol}$. As a general rule of thumb (recognizing this is a conservative estimate), the activation energy
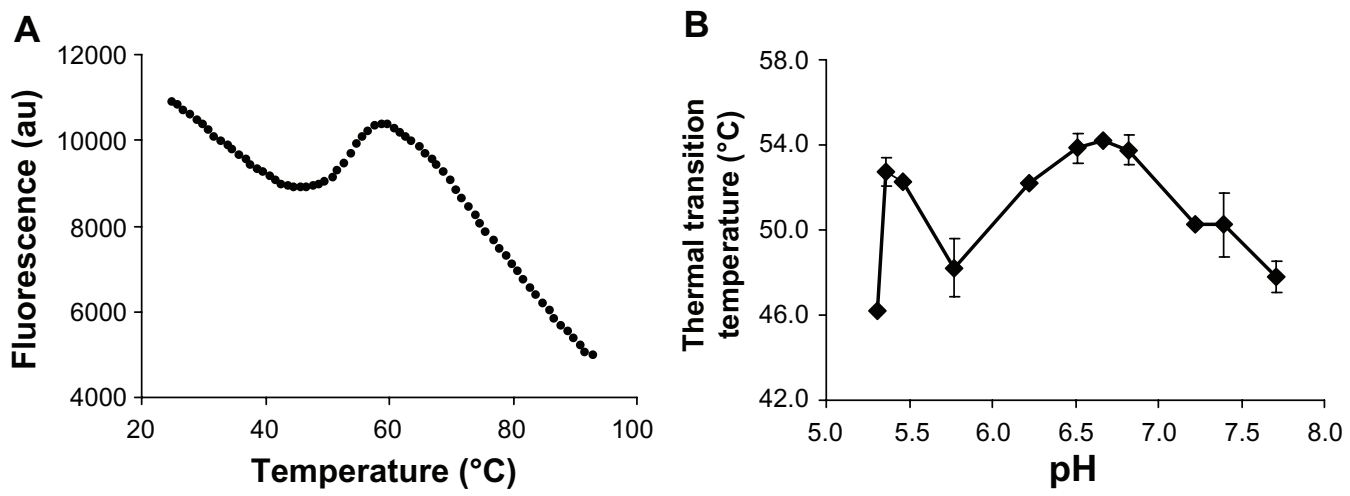

Figure 3 Effect of temperature and pH on enveloped viral stability. (A) Representative thermal profile of an enveloped attenuated model virus vaccine using SYBR Green ${ }^{\circledR}$ (Life Technologies, Carlsbad, CA, USA) as an extrinsic dye. A programmed heating cycle from room temperature to $95^{\circ} \mathrm{C}$ with a I ${ }^{\circ} \mathrm{C} /$ minute increment was used. (B) Effect of $\mathrm{pH}$ stress on the thermal transition temperature (diamonds) measured by extrinsic fluorescence of SYBR Green. 
doubles as the temperature increases by $10^{\circ} \mathrm{C}$ increments. With this information, the amount of time a vaccine sample should be stored to achieve energy equivalent of accelerated stability conditions can be calculated. The Arrhenius model attempts to predict the shelf life of a peptide/protein formulation based on the extrapolation of stability data from three temperature conditions (which include at least one real-time storage and two stress conditions). Extrapolation can be very useful in selecting formulations and or defining shelf life, especially since it can take up to 2 years to collect real-time data. However, Arrhenius modeling does not necessary work when there are parallel chemical reactions occurring as mentioned above, which is often the case for protein molecules. In this case, using this model could lead to over or under estimation of shelf life, when assuming linearity.

When proposing tentative shelf life durations for clinical material, thermal stress data can be used with real-time data at the normal storage condition. However, it is imperative that real-time data is collected and monitored in order to confirm accelerated stability predictions. A prediction of real time data from accelerated stability conditions is only possible if the conditions are qualitatively controlled by the same physicochemical factors (ie, formation of a conformationally changed intermediate). Therefore, it is important to conduct a comparison of this type of degradation mechanism using thermal stress conditions with real-time data at normal storage conditions.

\section{Freeze-thaw stress}

Freeze-thaw studies are conducted to assess the vaccine to ice-water interfaces in addition to low temperatures, which could lead to destabilizing the product. Freeze-thaw studies are necessary to support any temperature excursions that may occur during storage or shipment of the product, as well as to identify any potential excipients that may help to stabilize the product when frozen for either storage or during the lyophilization process. When designing a freeze-thaw experiment, factors to consider include the rate of freezing, concentration, and container geometry. ${ }^{89}$

It has been observed that freeze-thawing may induce aggregates and proteinaceous particles for protein based vaccines. ${ }^{90}$ High protein concentrations may be more resistant to surface induced aggregation. Therefore, studies on protein antigens need to be evaluated on a case-by-case basis on factors, such as interfacial stresses (protein/ice surface), cryoconcentration, crystallization of formulation excipients, phase separation, and $\mathrm{pH}$ shifts. ${ }^{1}$ Furthermore, the freezing rate may also affect the concentration gradients of a vaccine, whereby faster freezing rates generally result in fewer changes in the concentration gradient. ${ }^{91}$

The scale at which a freeze-thaw experiment is conducted is critical when designing these studies, since freezing at a larger scale can be different from a smaller scale. Small volumes (ie, 1-5 mL) can freeze homogeneously within minutes compared to larger volumes (ie, greater than $10 \mathrm{~mL}$ ). Larger volumes may not be as homogeneous with respect to protein concentration, $\mathrm{pH}$, and osmolarity. Greater protein concentration has been found in the middle and at the bottom of a container with large samples. ${ }^{89}$ Therefore, it is more difficult to extrapolate small scale freezing experiments to large scale.

Apart from the scale of the experiment, other variables that may influence vaccine stability during freeze-thaw studies include cooling rate, temperature at the beginning and end of freezing process, and filling volume. Cooling rate is one of the most important factors. This parameter deals with controlling the amount and size of ice crystals, as well as the dimension of the interfacial area between ice and freeze-concentrated solutions. ${ }^{92}$ Cooling rate can be classified as either slow $\left(<1^{\circ} \mathrm{C} /\right.$ minute $)$, intermediate $\left(\sim 5^{\circ} \mathrm{C} /\right.$ minute $)$, and fast $\left(10^{\circ} \mathrm{C}-900^{\circ} \mathrm{C} /\right.$ minute $) . .^{92}$ The cooling rate compared to the actual temperature of the product within the container can be different. These differences could be due to the nature of the product, filling volume, container used, and formulation composition. For example, when conducting fast freezing, liquid nitrogen is primarily used, which may lead to many small ice crystals and a larger interfacial area. This may increase the instability of the protein depending on the sensitivity of the protein towards surface-induced denaturation. In addition, thawing rates that include thawing temperatures and agitation can also influence the stability of the formulations.

When designing a freeze-thaw experiment it is sometimes easier to conduct a simple experiment where vials with liquid formulation are placed into a freezer and thawed at room temperature in order to gain insight into the general robustness of a protein antigen. Furthermore, experiments with controlled freezing and thawing conditions should follow multiple freeze-thaw cycles, and be assessed using stability-indicating assays. As discussed, the scale of the experiment is critical and should be considered when looking at either the drug substance or the drug product material. In Figure 4A, an example of a freeze-thaw study conducted on an immunomodulatory lipid suspension used as a vaccine adjuvant is shown. The particle size of the lipid suspension significantly increased as a result of freeze-thawing, while little to no changes were observed in lipid concentration. The 


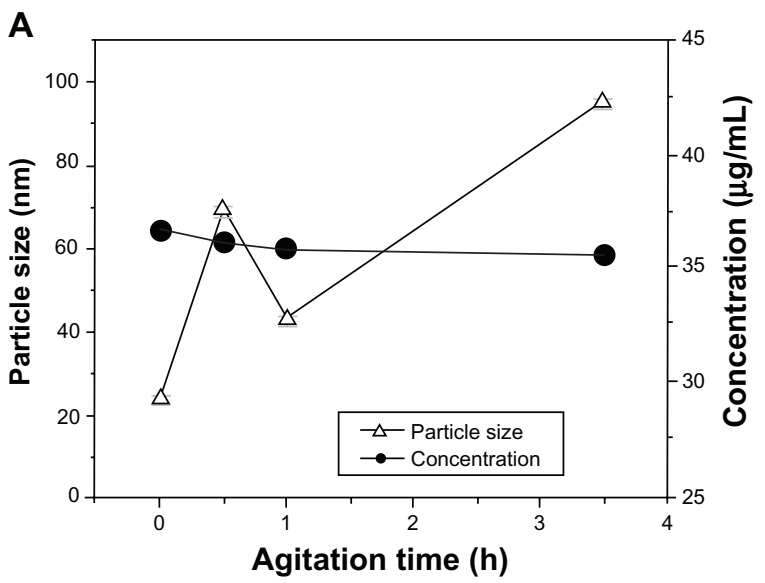

B

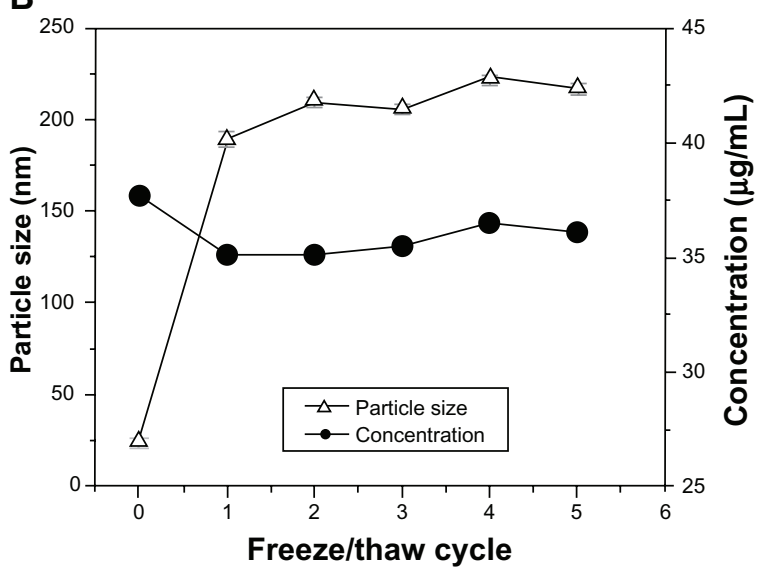

Figure 4 Effect of freeze-thawing and mechanical stress on particle size and concentration of an immunomodulatory lipid suspension. (A) Freeze-thawing; (B) mechanical stress.

Abbreviation: h, hours.

results suggest fusion or aggregation of lipid particles, probably induced by the interaction with the ice/liquid interface during freeze-thawing.

\section{Mechanical stress}

Mechanical stress is a common stress that vaccine components are exposed to during manufacturing, transportation, and final administration. Stress factors (ie, shaking, shearing, liquid filtration, and filling under pressure) must be assessed during preformulation/formulation development. These factors can have significant detrimental effects on the vaccine. It is consequently critical to test formulation robustness against these stress factors.

Surfactants excipients are added to the formulations to help reduce surface-induced aggregation due to mechanical stress. Stress testing such as agitation (shaking or stirring), pumping, vortexing, sonication, and special shearing, are all used to investigate the effects on vaccine formulations that may include surfactants. During stress studies, protein antigens could exhibit physical and chemical instability.
The manufacturing process and experimental design gives relevance to the different stresses required for testing.

During the manufacturing process, proteins are exposed to shear (ie, pumping, filtration, and mixing). However, the literature indicates that, in most cases, shear stress is not a major factor with respect to aggregation (even at high shear rates of 250,000 seconds $\left.{ }^{-1}\right) .{ }^{93}$ Conversely, mechanical stress testing experiments have shown that the air-liquid interfaces causing aggregation and/or particle formation can have a great impact on the formulation. Furthermore, severe aggregation during agitation of vials with greater air-headspace compared to less air-headspace has been observed. ${ }^{94}$ Foaming of protein after agitation studies affects the air-liquid interface and can potentially induce oxidation. ${ }^{94}$

The experimental design for mechanical stress studies is dependent on the stage of development and the condition being studied. Stirring and pumping stresses can be assessed to understand the manufacturing processes (ie, mixing or filling of the drug product material). Based on the representative manufacturing step, parameters should be selected accordingly. ${ }^{94}$ As a rapid screening test for the appropriate surfactants and stabilizers, agitation studies (ie, shaking) can be conducted during preformulation development to help mitigate aggregation due to mechanical stress. Stirring, which is considered a harsher stress than shaking, may be used during these studies. ${ }^{94} \mathrm{~A}$ common agitation test for various formulations includes using a lab bench shaker at approximately $350 \mathrm{rpm}$ for 3.5 hours at room temperature. Aggregation and particulate studies have been conducted recently to highlight protein nucleation due to the interaction of micro- and nanoparticles shed by protein contact surfaces during manufacturing. These included pumps, tubing, filters, and container closure systems. ${ }^{12}$ It is recommended that stress protocols evaluate the air-water interface using different storage materials, such as glass, cellulose, stainless steel, and iron (III) oxide microparticles for aggregation adsorption effects.

The effects of surface-induced aggregation on a recombinant protein antigen under different buffering conditions are shown in Figure 5. All formulations were clear, colorless solutions at the beginning of the study. After 24 hours of agitation, aggregation and precipitation were observed in the control samples. The addition of Tween 80 at $0.5 \%$ to the formulation was able to prevent particulate formation and precipitation against mechanical stress.

As another example, we show the mechanical stress study applied to a lipid immunostimulator. An increase of particle size was observed when the lipid suspension was subjected to a couple of hours of mechanical stress, suggesting surfaceinduced aggregation or fusion of lipid particles induced by 


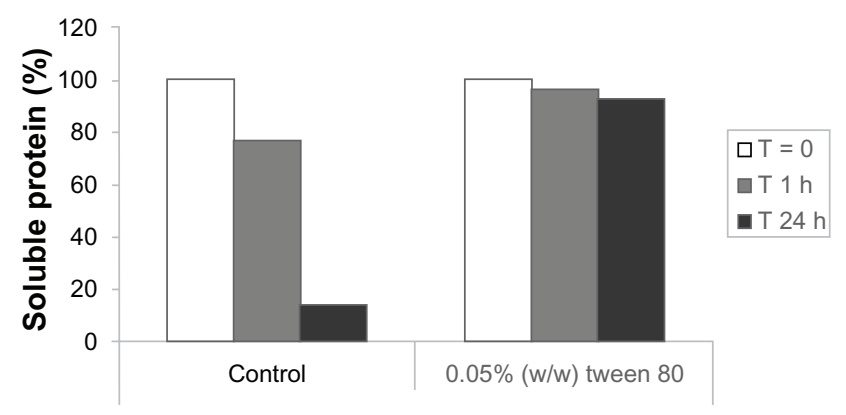

Figure 5 Effect of Tween 80 on protein solubility for formulation subjected to mechanical stress for up to 24 hours.

Notes: UV280 was used to quantify protein in supernatant.

Abbreviations: T, time; h, hour.

the air-water interface (Figure 4B). The small decrease in total concentration of lipid may suggest precipitation of large particles or adsorption to the container.

\section{Light stress}

There are many situations where vaccines are exposed to light. These include exposure to artificial or sunlight during production, shipment, storage, and administration in the clinic. Most vaccines on the market indicate on the label, "protect from direct light," and are distributed with appropriate secondary packaging to ensure the vaccine is protected from direct and long-term exposure of light.

Degradation due to light exposure depends on a number of factors, including the type of viral membrane or protein structure/conformation, the product formulation composition, the wavelength and intensity, and the duration of the exposure. Amino acids such as Cys, Trp, Tyr, and Phe are known to degrade upon absorption of light. Higher order aggregates, due to intermolecular covalent cross-links, may form. These aggregates are caused by the oxidation of Trp that subsequently forms kyneurenine and Tyr, which forms dityrosine. Both kyneurenine and dityrosine have unique fluorescence spectra and can be easily monitored. In addition, disulfide bonds may be formed by Cys radical anions. ${ }^{95}$

The current ICH guideline, Q1B, ${ }^{3}$ should be reviewed when designing a photostability study for new vaccines products. The guideline recommends using a combination of a cool white fluorescent lamp with a near-UV lamp. The ICH Q1B makes a distinction between "force degradation testing studies" and "confirmatory testing studies." It recommends the conditions used for confirmatory studies in order to predict the stability of the product. The conditions include exposure to at least 1.2 million lux hours of visible light (400-800 nm) and at least $200 \mathrm{~W}$ hour $/ \mathrm{m}^{2}$ of UV light
(320-400 nm). Any significant observable changes under these confirmatory conditions results in a product recommendation to be protected from direct light and have adequate packaging. In the case of FD studies, the guideline does not recommend specific conditions that increase understanding of vaccine photosensitivity and elucidate degradation pathways. However, a variety of exposure conditions higher than those recommended for confirmatory testing can be applied. Identifying parameters, such as exposure time during manufacturing, fill/finish, and clinical step up and wavelength of light source can help with designing the photostability study. In addition, proper controls such as light protected samples are essential.

In our laboratory, a photostability study was performed to evaluate an enveloped attenuated virus at $25^{\circ} \mathrm{C}$ after light stress. Four exposure conditions were applied to the viral material using a Caron 6540 Series Photostability Chamber (Caron Products and Services, Inc, Marietta, $\mathrm{OH}$, USA). Each condition contained both control samples and experimental samples. Control vials were wrapped with aluminum foil to prevent any light exposure. The control and experimental vials were placed horizontally in the chamber, to ensure maximal light exposure. Since viruses are known to be sensitive to light, it was suggested to test the ICH recommended exposure parameter as well as lower exposure conditions. Figure 6 shows log titer results for condition A (50\% of ICH recommended visible light exposure) and condition B (50\% of ICH recommended visible light and UV exposure). The results illustrate the high sensitivity of

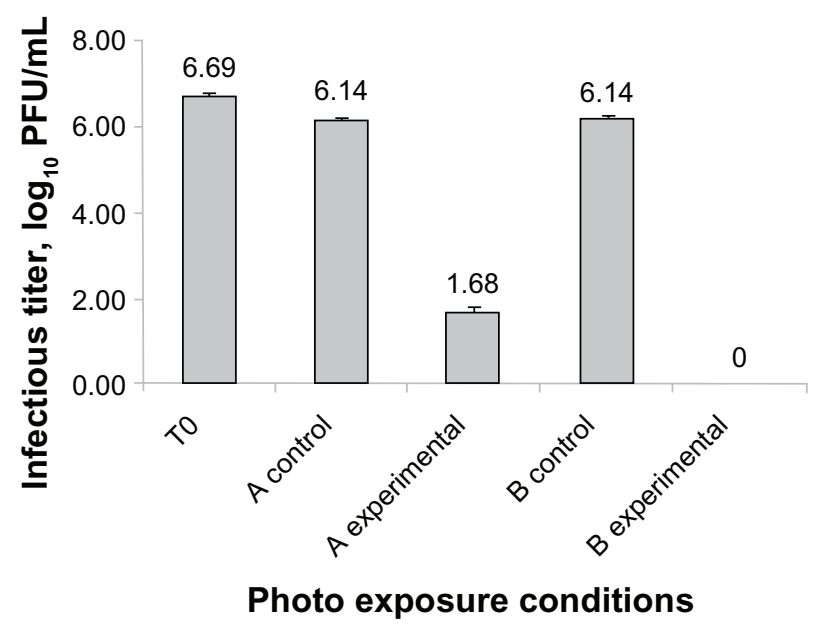

Figure 6 Plaque assay results for an enveloped virus photostability study. Notes: Condition A consisted of $50 \%$ visible light illuminance based on the $\mathrm{ICH}$ recommended exposure, while condition $\mathrm{B}$ consisted of $50 \%$ visible light illuminance and $50 \% \mathrm{UV}$ irradiance based on the $\mathrm{ICH}$ recommended exposure.

Abbreviations: ICH, International Conference on Harmonization; UV, ultraviolet. 
this virus to light in which a greater titer loss was observed compared to the control sample.

\section{Oxidation stress}

Protein oxidation is a common phenomenal that requires investigation during formulation development. It can be caused by a variety of factors such as the presence of peroxides (ie, using less pure polysorbate), metal ions from stainless steel surfaces, residues of aseptic agents (used in isolators), and light. ${ }^{1}$ Oxidation stress is often used to gather product knowledge by elucidating degradation pathways and kinetics or assay development. ICH Q1A recommends that the oxidation of the drug substance be assessed; however, it does not define the conditions that should be used. ${ }^{96}$

Oxidation can either be site-specific or nonsite-specific. In the case of site-specific oxidation, amino acid residuals such as His, Met, Cys, Tyr, and Trp are highly sensitive to oxidation. On the other hand, nonsite-specific reactions include photo-oxidation and oxidation, involving free radicals or ROS.

Common oxidation stress studies include using low levels of $\mathrm{H}_{2} \mathrm{O}_{2}(0.01 \%-0.1 \%)$, tert-butyl hydroperoxide $(0.1 \%-1 \%)$, or ozone at ambient temperatures. The European Pharmacopeia describes an oxidation procedure using $0.005 \%(\mathrm{v} / \mathrm{v}) \mathrm{H}_{2} \mathrm{O}_{2}$ for 20 hours at $37^{\circ} \mathrm{C}$. Forced oxidation in proteins can also be conducted by incubating samples with increasing concentrations of $\mathrm{H}_{2} \mathrm{O}_{2}$ under normal or accelerated temperatures. As an example, RP-HPLC results for the forced oxidation of a protein antigen conducted at room temperature are shown in Figure 7. In these experiments, the normal profile of the protein was significantly altered by the addition of $\mathrm{H}_{2} \mathrm{O}_{2}$. A shoulder began to appear at $\sim 19$ minutes and as low as $25 \mathrm{mM} \mathrm{H}_{2} \mathrm{O}_{2}$. At higher $\mathrm{H}_{2} \mathrm{O}_{2}$ concentrations, a complete shift to lower retention times with respect to the normal retention time of the protein was observed. These results are compatible with Met oxidation, as degradation products are known to confer higher polarity to the molecule, which may explain the low retention time of the oxidized protein

The concentration of $\mathrm{H}_{2} \mathrm{O}_{2}$ is not the only factor affecting the degree of oxidation, as the $\mathrm{pH}$ of the solution can also influence the amount of oxidation. For example, Met residues can become accessible due to $\mathrm{pH}$ induced conformational changes, consequently affecting the degree of oxidation. Furthermore, a combination of certain metal ions, such as $\mathrm{Fe}_{\text {(III) }}$ or $\mathrm{Cu}_{\text {(II) }}$, have been used as oxidation agents and can be used when designing oxidation protocols. Oxidation of amino acids makes the protein molecule more hydrophilic, and therefore, chromatographic methods may be used to monitor oxidation of intact protein as an analytical tool.

In addition, as shown in Figure 8, an enveloped virus oxidation study was conducted at three concentrations of $\mathrm{H}_{2} \mathrm{O}_{2}, 0.006 \%, 0.03 \%$, and $0.06 \%$, respectively. The samples were incubated at $25^{\circ} \mathrm{C}$ for 24 hours to allow the oxidation reactions to occur. A plaque assay test was then conducted to test for infectious titer. Compared to the control sample, there was a $0.48 \log$ titer loss when $0.006 \% \mathrm{H}_{2} \mathrm{O}_{2}$ was pres-

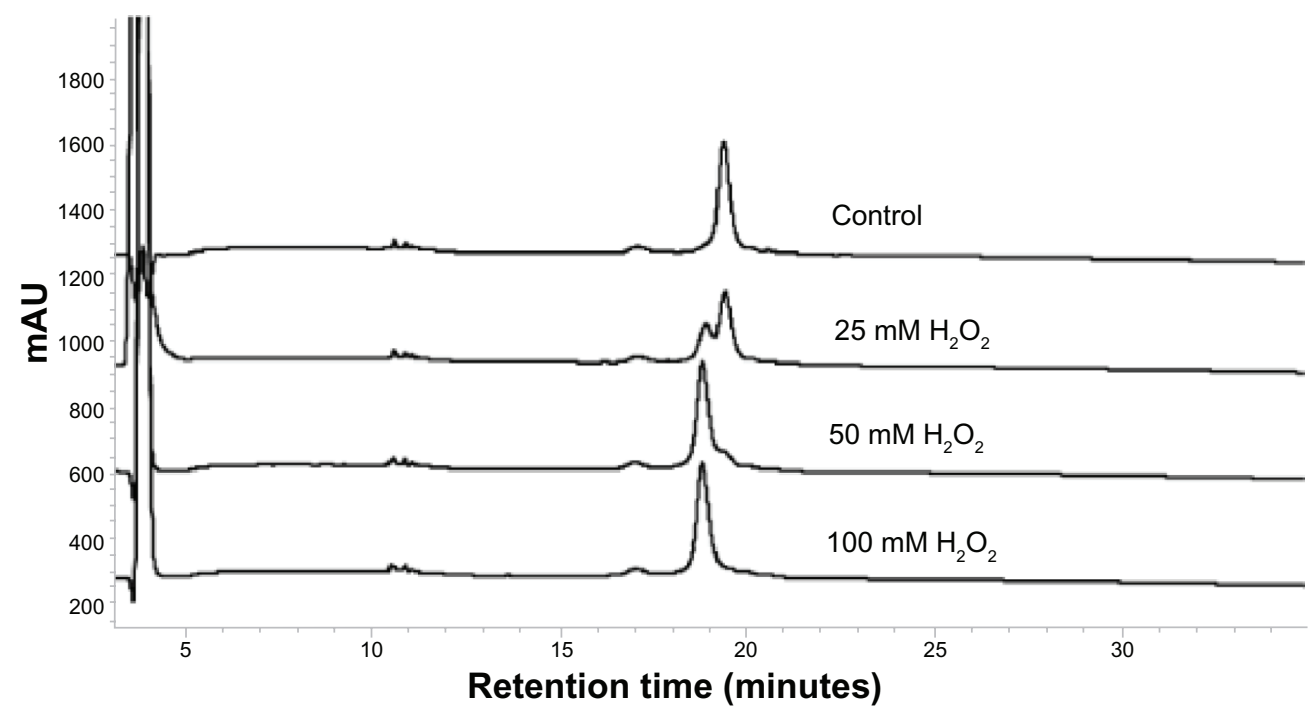

Figure 7 Effect of increasing the concentration of $\mathrm{H}_{2} \mathrm{O}_{2}$ on the RP-HPLC profile of a pneumococcal vaccine antigen.

Notes: The antigen was treated with increasing concentrations of $\mathrm{H}_{2} \mathrm{O}_{2}$ for 15 minutes at room temperature, and then analyzed by RP-HPLC. A shift in the retention time was observed upon forced oxidation.

Abbreviation: RP-HPLC, reversed phase high-performance liquid chromatography. 


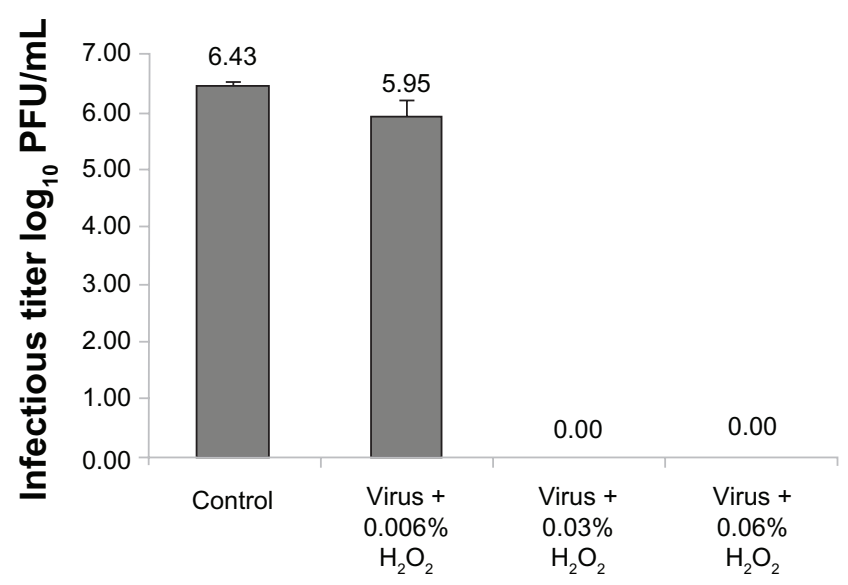

Figure 8 Plaque assay results of an enveloped attenuated virus oxidized at $0.006 \%$, $0.03 \%$, and $0.06 \%$ of $\mathrm{H}_{2} \mathrm{O}_{2}$.

Notes: The control samples were wrapped with aluminum foil versus the experimental samples in glass vials. The study was performed at ambient temperature for up to approximately 24 hours.

ent in the solution. As the concentration of $\mathrm{H}_{2} \mathrm{O}_{2}$ increased to $0.03 \%$ or $0.06 \%$, a complete titer loss was observed. The results suggested that oxidation reactions with peroxide radicals caused loss of viral activities. From this study, it becomes obvious that oxidation was one of the degradation pathways for this particular virus.

\section{Stabilizers and vaccine excipients}

In vaccines, pharmaceutical excipients may be added to the formulation for a number of reasons, such as to stabilize a specific component of the vaccine, modulate adsorption to adjuvants, maintain formulation tonicity, and control formulation $\mathrm{pH}$.

There are many categories of pharmaceutical excipients used in the formulation and stabilization of vaccines; they range from simple small buffer molecules to more complex and sophisticated polymers. A summary of commonly used pharmaceutical excipients for commercial vaccines is depicted in Table 4.

\section{Buffering components and inorganic salts}

Maintenance of both chemical and physical macromolecular stability is highly dependent on the solution $\mathrm{pH}$. Chemical reactions in protein-based antigens can be slowed down or prevented within a certain $\mathrm{pH}$. Many pharmaceutical acceptable buffering agents are used to control solution $\mathrm{pH}$ in vaccines, including acetate, citrate, His, phosphate, and Tris, borate. These buffering agents cover a broad $\mathrm{pH}$ range. Inorganic salts, such as sodium chloride $(\mathrm{NaCl})$, are typically added to buffers to adjust tonicity and thus pre-

Table 4 Common pharmaceutical excipients used in vaccines

\begin{tabular}{|c|c|c|c|c|}
\hline $\begin{array}{l}\text { Excipient } \\
\text { category }\end{array}$ & $\begin{array}{l}\text { Representative } \\
\text { examples }\end{array}$ & $\begin{array}{l}\text { Proposed mechanism } \\
\text { of action }\end{array}$ & Vaccine examples & $\begin{array}{l}\text { Working } \\
\text { concentration range }\end{array}$ \\
\hline \multirow[t]{2}{*}{ Inorganic salts } & $\mathrm{NaCl}, \mathrm{KCl}$ & Adjust tonicity & Many examples & $0.5 \%-1 \% \mathrm{w} / \mathrm{v}$ \\
\hline & $\mathrm{MgCl}_{2}$ & Specific stabilization & Oral polio vaccine & $0.45-3 \mathrm{M}$ \\
\hline \multirow[t]{3}{*}{ Buffering agents } & Phosphate buffer & $\begin{array}{l}\text { Maintain solution } \mathrm{pH} \text {, modulation } \\
\text { of antigen binding to } \mathrm{Al} \text { salt adjuvants }\end{array}$ & $\begin{array}{l}\text { Cervarix }^{\circledR} \text {, Flumist }{ }^{\circledR}, \text { Menactra } \\
\text { Experimental pneumoccocal vaccine }\end{array}$ & $2-20 \mathrm{mM}$ \\
\hline & Succinate buffer & Maintain solution $\mathrm{pH}$ & Prevnar $13^{\circledR}$ & $300 \mu \mathrm{g} / \mathrm{dose}$ \\
\hline & Sodium borate & Maintain solution $\mathrm{pH}$ & Gardasil $^{\circledast}$, Vaqta ${ }^{\circledR}$ & $35 \mu \mathrm{g} /$ dose \\
\hline \multirow[t]{2}{*}{ Surfactants } & $\begin{array}{l}\text { Polysorbate } 20 \\
\text { and } 80\end{array}$ & $\begin{array}{l}\text { Prevent protein aggregation } \\
\text { at interfaces }\end{array}$ & Boostrix $^{\circledast}$, Fluarix $^{\circledR}$, Pentace ${ }^{\circledR}$ & $10-425 \mu \mathrm{g} /$ dose \\
\hline & Triton X-100 & Split viral particles & $\begin{array}{l}\text { FluZone }^{\circledast} \\
\text { Fluarix }^{\circledast}\end{array}$ & $50-250 \mu \mathrm{g} /$ dose \\
\hline \multirow[t]{3}{*}{ Amino acids } & L-glutamate & Specific interaction with proteins & RabAvert $^{\circledR}$, FluMist $^{\circledast}$, Zostava $^{\circledR}$ & $0.3-0.6 \mathrm{mg} /$ dose \\
\hline & L-arginine & Inhibition of aggregation & Experimental RSV and malaria vaccine & $0.15-0.45 \mathrm{M}$ \\
\hline & L-histidine & $\begin{array}{l}\text { Specific interaction with proteins, } \\
\text { antioxidant, buffering agent }\end{array}$ & $\begin{array}{l}\text { Gardasi }{ }^{\circledR}, \text { monoclonal antibody } \\
\text { formulations }\end{array}$ & $0.78 \mathrm{mg} /$ dose \\
\hline \multirow[t]{2}{*}{$\begin{array}{l}\text { Sugars and } \\
\text { polyols }\end{array}$} & Sucrose & $\begin{array}{l}\text { Preferential hydration, increase } \\
\text { interfacial tension in lipid bilayers }\end{array}$ & $\begin{array}{l}\text { FluMist }^{\circledR}, J V a x^{\circledast}, M-M-R^{\circledast}, \text { ActHIB } \\
\text { Rotarix }^{\circledast}\end{array}$ & $1 \%-8.5 \% \mathrm{w} / \mathrm{v}$ \\
\hline & Sorbitol & $\begin{array}{l}\text { Preferential hydration, increase } \\
\text { interfacial tension in lipid bilayers }\end{array}$ & M-M-R ${ }^{\circledR}$, Proquad $^{\circledR}$, YF vax ${ }^{\circledR}$ & $1.8-14.5 \mathrm{mg} / \mathrm{dose}$ \\
\hline Proteins & Albumin, gelatin & $\begin{array}{l}\text { Unknown; inhibitor of protein } \\
\text { aggregation by competitive mechanism }\end{array}$ & $\begin{array}{l}\text { Imovax }^{\circledast}, \text { M-M-R }{ }^{\circledR}, \text { RotaTaq }^{\circledast}, \\
\text { RabAver }^{\circledast}, \text { Varivax }^{\circledast}\end{array}$ & $\begin{array}{l}\text { Variable, up } \\
\text { to }<100 \mathrm{mg} / \text { dose }\end{array}$ \\
\hline \multirow[t]{3}{*}{ Antioxidants } & $\begin{array}{l}\text { EDTA and citric } \\
\text { acid }\end{array}$ & Chelating agents & FluMist $^{\circledR}$, RabAvert $^{\circledR}$, Varivax $^{\circledR}$ & $\begin{array}{l}\text { Up to } 0.3 \mathrm{mg} \\
\text { EDTA/dose }\end{array}$ \\
\hline & Ascorbic acid & Oxygen scavenger & Vivotif $^{\circledR}$ & Up to $5 \mathrm{mg}$ \\
\hline & Metabisulphite & Oxygen scavenger & |xiaro ${ }^{\circledR}$ & $\leq 200$ ppm \\
\hline
\end{tabular}

Abbreviations: RSV, respiratory synctial virus; MMR, measles, mumps, rubella; EDTA, ethylenediaminetetraacetic acid. 
vent pain upon injection. Inorganic salts are also added to vaccine formulation as stabilizers. For instance, magnesium chloride $\left(\mathrm{MgCl}_{2}\right)$, has been suggested to stabilize the capsid of hepatitis A virus and poliovirus. ${ }^{97,98}$

Buffering agents and inorganic salts can be added to the formulation to modulate and stabilize antigens adsorbed to aluminum salts. ${ }^{23}$ Phosphate ions at low concentration can be added to $\mathrm{AH}$ containing formulation, to decrease the deleterious effect of high microenvironment $\mathrm{pH}$ on adsorbed antigens. We have recently shown that the stability of three adsorbed pneumococcal protein antigens can be improved by pretreatment of $\mathrm{AH}$ with $2 \mathrm{mM}$ phosphate. ${ }^{72}$ Furthermore, as shown in Figure 9, the chemical stability of the pneumococcal antigen PcpA was improved by phosphate treatment of AH (PT-AH). A similar trend was observed for two other recombinant pneumococcal antigens investigated. ${ }^{72}$

\section{Surfactants}

Nonionic surfactants are often added to formulations to prevent aggregation of formulation components due to mechanical stresses, such as shaking or agitation, or to prevent adsorption to different surfaces. Common surfactants added to formulations, include polysorbate 20 , polysorbate 80 , triton X100, and Pluronic F68. Surfactants have been shown to prevent a variety of physical instability, including proteinprotein association, surface induced aggregation, precipitation, and adsorption to container surfaces. The prevention of surface-induced aggregation is a typical example of the use of surfactants. Surfactants molecules compete with the protein for the adsorption to hydrophobic surfaces, such as air bubbles, preventing the adsorption and denaturation of proteins in the interface. ${ }^{99}$

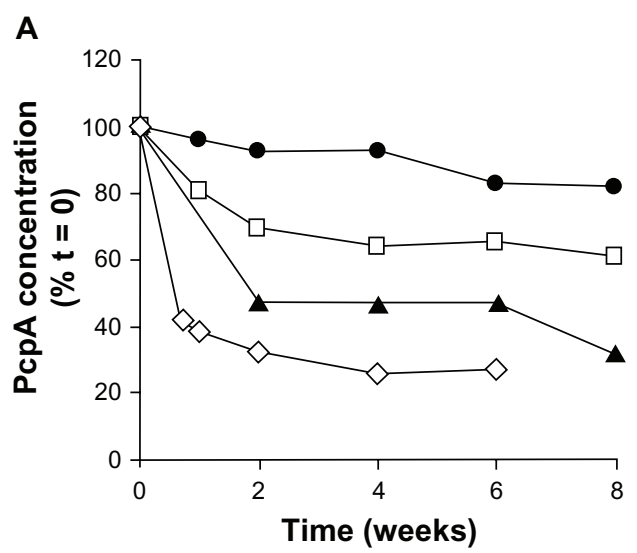

In addition to the prevention of aggregation and precipitation of the vaccine, surfactants such as Triton X-100, are used in influenza vaccines to disintegrate the virus particles in split vaccine as well as to guarantee the homogeneity during production. ${ }^{100}$

\section{Amino acids}

Amino acids are well known stabilizers for protein-based pharmaceuticals and vaccines. These molecules act by diverse mechanisms, including preferential hydration, prevention of aggregation, and direct binding to protein molecules.

The most common amino acids found in vaccines are glutamic acid (as sodium salt), arginine, and His (see Table 4). Histidine is a very common buffer in biotherapeutic formulations, particularly in monoclonal antibody formulations. This amino acid is used to control $\mathrm{pH}$ and physically stabilize monoclonal antibodies by direct noncovalent interactions. ${ }^{101}$ Histidine has the added value of being an antioxidant that acts as free radical scavenger. Glutamic acid and arginine have been shown to increase protein solubility by hydrogen bonding interactions between the excipients on the surface of the protein. ${ }^{102}$ Monosodium L-glutamate and arginine are used as stabilizers in several liquid live viral vaccines; ${ }^{103}$ however, its effects are not well understood.

\section{Sugars and polyols}

Sugars and polyols are used by nature to stabilize microorganisms to harsh conditions of the environment. These compounds are believed to stabilize the folded state of proteins as a result of preferential hydration. ${ }^{104}$ They are also believed to produce an increase in the structural order and a compaction

\section{B}

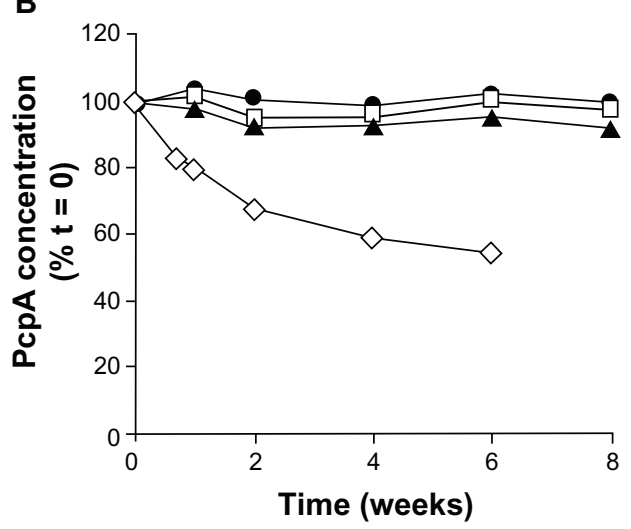

Figure 9 Stability profiles at $5^{\circ} \mathrm{C}, 25^{\circ} \mathrm{C}, 37^{\circ} \mathrm{C}$, and $45^{\circ} \mathrm{C}$ for PcpA in trivalent formulations adjuvanted with $\mathrm{AH}$ and $\mathrm{PT}-\mathrm{AH} .{ }^{84}(\bullet) 5^{\circ} \mathrm{C},(\square) 25^{\circ} \mathrm{C},(\boldsymbol{\Delta}) 37^{\circ} \mathrm{C}$, and $(\diamond) 45^{\circ} \mathrm{C}$ for PcpA in trivalent formulations adjuvanted with (A) AH and (B) PT-AH.

Note: Ljutic et al. Vaccine 2012; 20:298I-2988. Copyright 2012, reproduction with permission of Elsevier. ${ }^{72}$

Abbreviations: $\mathrm{AH}$, aluminum hydroxide; $\mathrm{PT}-\mathrm{AH}$, phosphate treatment of aluminum hydroxide; PcpA, pneumococcal choline binding protein $\mathrm{A}$; $\mathrm{t}$, time. 
of the native state resulting in lower conformational mobility of proteins. In live viral vaccines, sugars and polyols were shown to induce an increase in the gel-to-liquid crystalline phase transition of the lipid envelope of respiratory syncytial virus. ${ }^{61,62}$ Sugars and polyols are proposed to increase the stability of hydrated membranes due to their water-structuring properties, causing the lipid bilayer to become more closely packed due to an increase in interfacial tension. ${ }^{105}$

\section{Proteins as stabilizers}

Human serum albumin and bovine serum albumin, as well as animal-derived gelatin, are frequent stabilizer of vaccines. Albumin and gelatin are found as stabilizer of the measles, mumps, and rubella (M-M-R ${ }^{\circledR}$; Merck and Co, Inc., Whitehouse Station, NJ, USA) vaccine, the rabies vaccine (RabAvert ${ }^{\circledR}$; Novartis International, AG, Basel, Switzerland), and varicella vaccine (Varivax ${ }^{\circledR}$; Merck and Co, Inc, Whitehouse Station, NJ, USA) (Table 4). The mechanism of action of these proteins is not well understood. They were proposed to inhibit aggregation by adsorbing to hydrophobic interfaces by a similar mechanism proposed for surfactants. The effects of recombinant human gelatin in protein stability were recently investigated, and it was proposed that gelatin can inhibit protein aggregation by interacting with the partially unfolded state through a combination of electrostatic and other intermolecular mechanisms. ${ }^{106}$

\section{Antioxidants}

Oxidation is a major degradation pathway occurring in vaccines, particularly oxidation reactions catalyzed by metals. At some point during processing, vaccine components may come in contact with catalyzing metals such as copper, iron, calcium, zinc, and manganese. Several antioxidants are available as pharmaceutical excipients to prevent oxidation. These agents fall into different categories.

Chelating agents - molecules such as ethylenediaminetetraacetic acid and citric acid, have been reported to prevent oxidation in protein pharmaceuticals, monoclonal antibody preparations, DNA, plasmid, and experimental adenovirus experimental vaccines. ${ }^{107}$ The addition of free radical scavengers was reported to enhance the effect of metal chelators. ${ }^{107}$

Preferentially oxidized compounds - these are substances that are more readily oxidized than the molecule they are protecting and act as oxygen scavengers. Examples of these agents in pharmaceutical preparations of vaccines are ascorbic acid (typhoid vaccine, Vivotif ${ }^{\circledR}$; Crucell, Leiden, The Netherlands) and sodium metabisulphite (Japanese encephalitis; Ixiaro $^{\circledR}$; Novartis International, AG, Basel,
Switzerland). However, it has been reported that in some cases, ascorbic acid can actually lead to oxidation of proteins in the presence of certain metal ions. ${ }^{101}$

Chain terminators - these substances react with free radicals in solution to produce a new species, which does not reenter the radical propagation cycle. Thiol-containing molecules, such as Cys and methionine, are examples of chain terminators.

\section{Final considerations}

In addition to the well-recognized role in the development of stability-indicating assays, FD studies are essential for the formulation development of vaccines. Such studies have the ability to unveil degradation pathways and instability issues that the formulation scientist will be facing down the road. Although much is known about the degradation pathways for relatively simply macromolecules (ie, proteins, lipids, and polysaccharides), our knowledge of the molecular events that lead to losses of biological activity of macromolecular complexes and entire microorganisms used in vaccines is very limited. We strongly believe that the implementation of an FD strategy along with the appropriate analytical technology are pivotal for understanding the instability of vaccines at a molecular level that will lead to the development of more stable and well characterized formulations of modern vaccines.

Partnership between regulatory agencies and vaccine developers will facilitate to fill the gaps of existing silent regulations by providing guidance on minimum requirements for setting up FD studies for biologics.

\section{Acknowledgments}

The authors thank Joyce Javier and Elizabeth Srokowski for excellent technical assistance in the preparation of this manuscript.

\section{Disclosure}

The authors report no conflicts of interest in this work.

\section{References}

1. Hawe A, Wiggenhorn M, van de Weert M, Garbe JH, Mahler HC, Jiskoot W. Forced degradation of therapeutic proteins. J Pharm Sci. 2012;101(3):895-913.

2. Kats M.[webpage on Internet]. Forced Degradation Studies: Regulatory Considerations and Implementation; 2005. Available from: http:// www.biopharminternational.com/biopharm/article/articleDetail. jsp?id=170505

3. International Conference on Harmonization. Q1B: Photostability Testing of New Drug Substances and Products. US Department of Health and Human Services; Rockville, MD: 1997;62(95):27115-27122.

4. International Conference on Harmonization. Q2(R1): Validation of Analytical Procedures: Text and Methodology. London, UK: European Medicines Agency; 1995;60(11260):27463-27467. 
5. International Conference on Harmonization. Q3A(R2): Impurities in New Drug Substances. Published in the Federal Register on Jun 2008.

6. International Conference on Harmonization. $Q 3 B(R 2)$ : Impurities in New Drug Products. London, UK: European Medicines Agency; 2003;68(220):64628-64629.

7. International Conference on Harmonization. Q5C: Stability Testing of Biotechnological/Biological Products. London, UK: European Medicines Agency; 1996;61:36466.

8. International Conference on Harmonization. ICH Q5E: Comparability of Biotechnological/Biological Products Subject to Changes in their Manufacturing Process. Silver Spring, MD: Food and Drug Administration; 2005;70(125):37861-37862.

9. International Conference on Harmonization. Q6B: Test Procedures and Acceptance Criteria for Biotechnological/Biological Products. London, UK: European Medicines Agency; 1999;64:44928.

10. International Conference on Harmonization. Q8(R2): Pharmaceutical Development. Published in the Federal Register, Nov 2009, Vol. 71.

11. International Conference on Harmonization. Q11: Development and Manufacture of Drug Substances. Silver Spring, MD: US Department of Health and Human Services; 2012;77(224):69634-69635.

12. Bee JS, Chiu D, Sawicki S, et al. Monoclonal antibody interactions with micro- and nanoparticles: adsorption, aggregation, and accelerated stress studies. J Pharm Sci. 2009;98(9):3218-3238.

13. Bhatt NP, Patel K, Borchardt RT. Chemical pathways of peptide degradation. I. Deamidation of adrenocorticotropic hormone. Pharm Res. 1990;7(6):593-599.

14. Chi EY, Krishnan S, Randolph TW, Carpenter JF. Physical stability of proteins in aqueous solution: mechanism and driving forces in nonnative protein aggregation. Pharm Res. 2003;20(9):1325-1336.

15. Manning MC, Chou DK, Murphy BM, Payne RW, Katayama DS. Stability of protein pharmaceuticals: an update. Pharm Res. 2010;27(4): 544-575.

16. Yan B, Steen S, Hambly D, et al. Succinimide formation at Asn 55 in the complementarity determining region of a recombinant monoclonal antibody IgG1 heavy chain. J Pharm Sci. 2009;98(10):3509-3521.

17. Wingfield PT, Mattaliano RJ, MacDonald HR, et al. Recombinantderived interleukin-1 alpha stabilized against specific deamidation. Protein Eng. 1987;1(5):413-417.

18. Doyle HA, Gee RJ, Mamula MJ. Altered immunogenicity of isoaspartate containing proteins. Autoimmunity. 2007;40(2):131-137.

19. Jenkins N, Murphy L, Tyther R. Post-translational modifications of recombinant proteins: significance for biopharmaceuticals. Mol Biotechnol. 2008;39(2):113-118.

20. Oliyai C, Patel JP, Carr L, Borchardt RT. Chemical pathways of peptide degradation. VII. Solid state chemical instability of an aspartyl residue in a model hexapeptide. Pharm Res. 1994;11(6):901-908.

21. Patel K, Borchardt RT. Chemical pathways of peptide degradation. III. Effect of primary sequence on the pathways of deamidation of asparaginyl residues in hexapeptides. Pharm Res. 1990;7(8):787-793.

22. Wakankar AA, Borchardt RT. Formulation considerations for proteins susceptible to asparagine deamidation and aspartate isomerization. J Pharm Sci. 2006;95(11):2321-2336.

23. Hem SL, HogenEsch H, Middaugh CR, Volkin DB. Preformulation studies - The next advance in aluminum adjuvant-containing vaccines Vaccine. 2010;28(31):4868-4870.

24. Clarke S, Stephenson RC, Lowenson JD. Lability of asparagine and aspartic acid residues in proteins and peptides: spontaneous deamidation and isomerization reactions. In Ahern T, Manning MC, editors. Stability of Protein Pharmaceuticals Part A: Chemical and Physical Pathways of Protein Degradation. New York, NY: Plenum Press; 1992:1-29.

25. Powell BS, Enama JT, Ribot WJ, et al. Multiple asparagine deamidation of Bacillus anthracis protective antigen causes charge isoforms whose complexity correlates with reduced biological activity. Proteins. 2007;68(2):458-479.

26. Estey T, Vessely C, Randolph TW, et al. Evaluation of chemical degradation of a trivalent recombinant protein vaccine against botulinum neurotoxin by LysC peptide mapping and MALDI-TOF mass spectrometry. J Pharm Sci. 2009;98(9):2994-3012.
27. Volkin DB, Mach H, Middaugh CR. Degradative covalent reactions important to protein stability. Mol Biotechnol. 1997;8(2):105-122.

28. George-Nascimento C, Lowenson J, Borissenko M, et al. Replacement of a labile aspartyl residue increases the stability of human epidermal growth factor. Biochemistry. 1990;29(41):9584-9591.

29. Liu WR, Langer R, Klibanov AM. Moisture-induced aggregation of lyophilized proteins in the solid state. Biotechnol Bioeng. 1991;37(2): 177-184.

30. Zhao Q, Wang Y, Abraham D, Towne V, Kennedy R, Sitrin RD. Real time monitoring of antigenicity development of HBsAg virus-like particles (VLPs) during heat- and redox-treatment. Biochem Biophys Res Commun. 2011;408(3):447-453.

31. Manning MC, Patel K, Borchardt RT. Stability of protein pharmaceuticals. Pharm Res. 1989;6(11):903-918.

32. Pogocki D, Ghezzo-Schöneich E, Schöneich C. Conformational flexibility controls proton transfer between the methionine hydroxy sulfuranyl radical and the N-terminal amino group in Thr-(X)n-Met peptides. J Phys Chem B. 2001;105(6):1250-1259.

33. Haensler J. Liposomal adjuvants: preparation and formulation with antigens. Methods Mol Biol. 2010;626:73-90.

34. Amanna IJ, Raué HP, Slifka MK. Development of a new hydrogen peroxide-based vaccine platform. Nat Med. 2012;18(6):974-979.

35. Reis A, Spickett CM. Chemistry of phospholipid oxidation. Biochim Biophys Acta. 2012;1818(10):2374-2387.

36. Jurkiewicz P, Olżyńska A, Cwiklik L, et al. Biophysics of lipid bilayers containing oxidatively modified phospholipids: Insights from fluorescence and EPR experiments and from MD simulations. Biochim Biophys Acta. 2012;1818(10):2388-2402.

37. Mosca M, Ceglie A, Ambrosone L. Effect of membrane composition on lipid oxidation in liposomes. Chem Phys Lipids. 2011;164(2): $158-165$.

38. Reis A, Domingues MR, Amado FM, Ferrer-Correia AJ, Domingues P. Separation of peroxidation products of diacyl-phosphatidylcholines by reversed-phase liquid chromatography-mass spectrometry. Biomed Chromatogr. 2005;19(2):129-137.

39. Demple B, Harrison L. Repair of oxidative damage to DNA: enzymology and biology. Annu Rev Biochem. 1994;63:915-948.

40. Middaugh CR, Evans RK, Montgomery DL, Casimiro DR. Analysis of plasmid DNA from a pharmaceutical perspective. J Pharm Sci. 1998;87(2):130-146.

41. Chen D, Kristensen D. Opportunities and challenges of developing thermostable vaccines. Expert Rev Vaccines. 2009;8(5):547-557.

42. Frasch CE. Preparation of bacterial polysaccharide-protein conjugates: analytical and manufacturing challenges. Vaccine. 2009;27(46): 6468-6470.

43. Sturgess AW, Rush K, Charbonneau RJ, et al. Haemophilus influenzae type $\mathrm{b}$ conjugate vaccine stability: catalytic depolymerization of PRP in the presence of aluminum hydroxide. Vaccine. 1999;17(9-10): 1169-1178

44. Putz MM, Ammerlaan W, Schneider F, Jung G, Muller CP. Humoral immune responses to a protective peptide-conjugate against measles after different prime-boost regimens. Vaccine. 2004;22(31-32):4173-4182.

45. Philo JS, Arakawa T. Mechanisms of protein aggregation. Curr Pharm Biotechnol. 2009;10(4):348-351.

46. Mahler HC, Friess W, Grauschopf U, Kiese S. Protein aggregation: pathways, induction factors and analysis. J Pharm Sci. 2009;98(9): 2909-2934.

47. Hutchings RL, M Singh S, Cabello-Villegas J, Mallela KM. Effect of antimicrobial preservatives on partial protein unfolding and aggregation. J Pharm Sci. 2013;102(2):365-376.

48. Majumdar S, Ford BM, Mar KD, Sullivan VJ, Ulrich RG, D’Souza AJ. Evaluation of the effect of syringe surfaces on protein formulations. J Pharm Sci. 2011;100(7):2563-2573.

49. Singh SK, Afonina N, Awwad M, et al. An industry perspective on the monitoring of subvisible particles as a quality attribute for protein therapeutics. J Pharm Sci. 2010;99(8):3302-3321.

50. Clapp T, Siebert P, Chen D, Jones Braun L. Vaccines with aluminumcontaining adjuvants: optimizing vaccine efficacy and thermal stability. J Pharm Sci. 2011;100(2):388-401. 
51. Bolgiano B, Mawas F, Yost SE, Crane DT, Lemercinier X, Corbel MJ. Effect of physico-chemical modification on the immunogenicity of Haemophilus influenzae type b oligosaccharide-CRM(197) conjugate vaccines. Vaccine. 2001;19(23-24):3189-3200.

52. Ratliff TL, Ritchey JK, Brandhorst J, Hanna MG Jr. Time-dependent aggregation of reconstituted BCG vaccine. J Urol. 1994;152(6 Pt 1): $2147-2150$.

53. Warren HS, Vogel FR, Chedid LA. Current status of immunological adjuvants. Annu Rev Immunol. 1986;4:369-388.

54. Salnikova MS, Davis H, Mensch C, Celano L, Thiriot DS. Influence of formulation $\mathrm{pH}$ and suspension state on freezing-induced agglomeration of aluminum adjuvants. J Pharm Sci. 2012;101(3):1050-1062.

55. Brandau DT, Jones LS, Wiethoff CM, Rexroad J, Middaugh CR. Thermal stability of vaccines. J Pharm Sci. 2003;92(2):218-231.

56. Cai S, He F, Samra HS, et al. Biophysical and stabilization studies of the Chlamydia trachomatis mouse pneumonitis major outer membrane protein. Mol Pharm. 2009;6(5):1553-1561.

57. Hu L, Joshi SB, Liyanage MR, et al. Physical characterization and formulation development of a recombinant pneumolysoid protein-based pneumococcal vaccine. J Pharm Sci. 2013;102(2):387-400.

58. Ausar SF, Foubert TR, Hudson MH, Vedvick TS, Middaugh CR. Conformational stability and disassembly of Norwalk virus-like particles. Effect of pH and temperature. J Biol Chem. 2006;281(28):19478-19488.

59. Kissmann J, Ausar SF, Foubert TR, et al. Physical stabilization of Norwalk virus-like particles. J Pharm Sci. 2008;97(10):4208-4218.

60. Ausar SF, Rexroad J, Frolov VG, Look JL, Konar N, Middaugh CR. Analysis of the thermal and $\mathrm{pH}$ stability of human respiratory syncytial virus. Mol Pharm. 2005;2(6):491-499.

61. Kissmann J, Ausar SF, Rudolph A, et al. Stabilization of measles virus for vaccine formulation. Hum Vaccin. 2008;4(5):350-359.

62. Ausar SF, Espina M, Brock J, et al. High-throughput screening of stabilizers for respiratory syncytial virus: identification of stabilizers and their effects on the conformational thermostability of viral particles. Hum Vaccin. 2007;3(3):94-103.

63. Volkin DB, Burke CJ, Marfia KE, Oswald CB, Wolanski B, Middaugh CR. Size and conformational stability of the hepatitis A virus used to prepare VAQTA, a highly purified inactivated vaccine. J Pharm Sci. 1997;86(6):666-673.

64. Burke CJ, Hsu TA, Volkin DB. Formulation, stability, and delivery of live attenuated vaccines for human use. Crit Rev Ther Drug Carrier Syst. 1999;16(1):1-83.

65. Ausar SF, Joshi SB, Middaugh CR. Spectroscopic methods for the physical characterization and formulation of nonviral gene delivery systems. Methods Mol Biol. 2008;434:55-80.

66. Chen V, Kim KJ, Fane AG. Effect of membrane morphology and operation on protein deposition in ultrafiltration membranes. Biotechnol Bioeng. 1995;47(2):174-180.

67. Kee GS, Pujar NS, Titchener-Hooker NJ. Study of detergent-mediated liberation of hepatitis B virus-like particles from S. cerevisiae homogenate: identifying a framework for the design of future-generation lipoprotein vaccine processes. Biotechnol Prog. 2008;24(3): 623-631.

68. Kim KJ, Chen V, Fane AG. Some factors determining protein aggregation during ultrafiltration. Biotechnol Bioeng. 1993;42(2): 260-265.

69. Russell WM, Burch RL. Prefatory Note. Altern Lab Anim. 2009;37(3): 267-268.

70. Habig WH. Potency testing of bacterial vaccines for human use. Vet Microbiol. 1993;37(3-4):343-351.

71. Festing MF. Reduction in animal use in the production and testing of biologicals. Dev Biol Stand. 1999;101:195-200.

72. Ljutic B, Ochs M, Messham B, et al. Formulation, stability and immunogenicity of a trivalent pneumococcal protein vaccine formulated with aluminum salt adjuvants. Vaccine. 2012;30(19):2981-2988.

73. Krell T, Manin C, Nicolaï MC, et al. Characterization of different strains of poliovirus and influenza virus by differential scanning calorimetry. Biotechnol Appl Biochem. 2005;41(Pt 3):241-246.
74. Jones LS, Peek LJ, Power J, Markham A, Yazzie B, Middaugh CR. Effects of adsorption to aluminum salt adjuvants on the structure and stability of model protein antigens. $J$ Biol Chem. 2005;280(14): 13406-13414.

75. Maddux NR, Joshi SB, Volkin DB, Ralston JP, Middaugh CR. Multidimensional methods for the formulation of biopharmaceuticals and vaccines. J Pharm Sci. Epub June 6, 2011.

76. Metz B, Hendriksen CF, Jiskoot W, Kersten GF. Reduction of animal use in human vaccine quality control: opportunities and problems. Vaccine. 2002;20(19-20):2411-2430.

77. Poland GA, Ovsyannikova IG, Johnson KL, Naylor S. The role of mass spectrometry in vaccine development. Vaccine. 2001;19(17-19): 2692-2700.

78. Metz B, Brunel F, Chamberlin C, et al. The potential of physicochemical and immunochemical assays to replace animal tests in the quality control of toxoid vaccines. The report and recommendations of ECVAM workshop 61. Altern Lab Anim. 2007;35(3):323-331.

79. Xing DK, Crane DT, Bolgiano B, Corbel MJ, Jones C, Sesardic D. Physicochemical and immunological studies on the stability of free and microsphere-encapsulated tetanus toxoid in vitro. Vaccine. 1996;14(13): $1205-1213$.

80. Ausar SF, Chan J, Hoque W, James O, Jayasundara K, Harper K. Application of extrinsic fluorescence spectroscopy for the high throughput formulation screening of aluminum-adjuvanted vaccines. $J$ Pharm Sci. 2011;100(2):431-440.

81. Costantino HR, Schwendeman SP, Griebenow K, Klibanov AM, Langer R. The secondary structure and aggregation of lyophilized tetanus toxoid. J Pharm Sci. 1996;85(12):1290-1293.

82. Carra JH, Wannemacher RW, Tammariello RF, et al. Improved formulation of a recombinant ricin A-chain vaccine increases its stability and effective antigenicity. Vaccine. 2007;25(21):4149-4158.

83. Sweeney JA, Sumner JS, Hennessey JP Jr. Simultaneous evaluation of molecular size and antigenic stability of PNEUMOVAX 23, a multivalent pneumococcal polysaccharide vaccine. Dev Biol (Basel). 2000;103:11-26.

84. Hutcheon CJ, Becker JO, Russell BA, Bariola PA, Peterson GJ, Stroop SD. Physiochemical and functional characterization of antigen proteins eluted from aluminum hydroxide adjuvant. Vaccine. 2006;24(49-50):7214-7225.

85. Rosenberg AS. Effects of protein aggregates: an immunologic perspective. AAPS J. 2006;8(3):E501-E507.

86. EMEA. Production and Quality Control of Monoclonal Antibodies and Related Substances. [EMEA/CHMP/BWP/15763/2007]. 2007.

87. Wilson GA, Manning MC. Flow imaging: moving toward best practices for subvisible particle quantitation in protein products. J Pharm Sci. 2013;102(3):1133-1134.

88. Plieskatt JL, Rezende WC, Olsen CM, et al. Advances in vaccines against neglected tropical diseases: enhancing physical stability of a recombinant hookworm vaccine through biophysical and formulation studies. Hum Vaccin Immunother. 2012;8(6):765-776.

89. Kolhe P, Badkar A. Protein and solute distribution in drug substance containers during frozen storage and post-thawing: a tool to understand and define freezing-thawing parameters in biotechnology process development. Biotechnol Prog. 2011;27(2):494-504.

90. Chang BS, Kendrick BS, Carpenter JF. Surface-induced denaturation of proteins during freezing and its inhibition by surfactants. $J$ Pharm Sci. 1996;85(12):1325-1330.

91. Treuheit MJ, Kosky AA, Brems DN. Inverse relationship of protein concentration and aggregation. Pharm Res. 2002;19(4):511-516.

92. Bhatnagar BS, Bogner RH, Pikal MJ. Protein stability during freezing: separation of stresses and mechanisms of protein stabilization. Pharm Dev Technol. 2007;12(5):505-523.

93. Maa YF, Hsu CC. Effect of high shear on proteins. Biotechnol Bioeng. 1996;51(4):458-465.

94. Eppler A, Weigandt M, Hanefeld A, Bunjes H. Relevant shaking stress conditions for antibody preformulation development. Eur J Pharm Biopharm. 2010;74(2):139-147. 
95. Kerwin BA, Remmele RL Jr. Protect from light: photodegradation and protein biologics. J Pharm Sci. 2007;96(6):1468-1479.

96. International Conference on Harmonization. Q1A(R2): Stability Testing of New Drug Substances and Products. Rockville, MD: US Department of Health and Human Services; 2003.

97. Volkin DB, Burke CJ, Sanyal G, Middaugh CR. Analysis of vaccine stability. Dev Biol Stand. 1996;87:135-142.

98. Melnick JL, Wallis C. Effect of $\mathrm{pH}$ on thermal stabilization of oral poliovirus vaccine by magnesium chloride. Proc Soc Exp Biol Med. 1963;112:894-897.

99. Bam NB, Cleland JL, Yang J, et al. Tween protects recombinant human growth hormone against agitation-induced damage via hydrophobic interactions. J Pharm Sci. 1998;87(12):1554-1559.

100. Lina B, Fletcher MA, Valette M, Saliou P, Aymard M. A TritonX100 -split virion influenza vaccine is safe and fulfills the committee for proprietary medicinal products (CPMP) recommendations for the European Community for Immunogenicity, in Children, Adults and the Elderly. Biologicals. 2000;28(2):95-103.

101. Kamerzell TJ, Esfandiary R, Joshi SB, Middaugh CR, Volkin DB. Protein-excipient interactions: mechanisms and biophysical characterization applied to protein formulation development. Adv Drug Deliv Rev. 2011;63(13):1118-1159.
102. Shukla D, Trout BL. Understanding the synergistic effect of arginine and glutamic acid mixtures on protein solubility. $J$ Phys Chem $B$. 2011;115(41):11831-11839.

103. Markus HZ, McAleer WJ, inventors; Merck \& Co, applicant. Vaccine stabilizer containing L-glutamic acid and L-arginine. United States patent US 4337242A. May 19, 1982.

104. Timasheff SN. Protein-solvent preferential interactions, protein hydration, and the modulation of biochemical reactions by solvent components. Proc Natl Acad Sci U S A. 2002;99(15):9721-9726.

105. Ricker JV, Tsvetkova NM, Wolkers WF, et al. Trehalose maintains phase separation in an air-dried binary lipid mixture. Biophys $J$. 2003;84(5):3045-3051.

106. Thyagarajapuram N, Olsen D, Middaugh CR. Stabilization of proteins by recombinant human gelatins. J Pharm Sci. 2007;96(12):3304-3315.

107. Evans RK, Nawrocki DK, Isopi LA, et al. Development of stable liquid formulations for adenovirus-based vaccines. J Pharm Sci. 2004;93(10):2458-2475.
Vaccine: Development and Therapy

\section{Publish your work in this journal}

Vaccine: Development and Therapy is an international, peer-reviewed, open access journal that spans the spectrum of vaccine design and development through to clinical applications. The journal is characterized by the rapid reporting of application notes, reviews, original research and clinical studies in all therapeutic areas. Clinical outcomes, patient safety,

\section{Dovepress}

and programs for the development and effective, safe, and sustained use of vaccines will be a feature of the journal. The manuscript management system is completely online and includes a very quick and fair peer-review system. Visit http://www.dovepress.com/testimonials.php to read real quotes from published authors.

Submit your manuscript here: http://www.dovepress.com/vaccine-development-and-therapy-journal 